Article (refereed)

R.T. Clarke \& J.F. Murphy.

Effects of locally rare taxa on the precision and sensitivity of RIVPACS bioassessment of freshwaters

Freshwater Biology 51(10) pp.1924-1940

Copyright 2006 Blackwell Publishing

This version available at http://nora.nerc.ac.uk/1805/

NERC has developed NORA to enable users to access research outputs wholly or partially funded by NERC. Copyright and other rights for material on this site are retained by the authors and/or other rights owners. Users should read the terms and conditions of use of this material at http://nora.nerc.ac.uk/policies.html\#access

This document is the author's final manuscript version of the journal article, incorporating any revisions agreed during the peer review process. Some differences between this and the publisher's version remain. You are advised to consult the publisher's version if you wish to cite from this article.

http://pubs.acs.org/cgi-bin/article.cgi/esthag/2008/42/i15/pdf/es702819f.pdf 
Abbreviated title: Effects of locally rare taxa on RIVPACS bioassessments

\section{Effects of locally rare taxa on the precision and sensitivity of RIVPACS bioassessment of freshwaters}

\section{R.T. CLARKE \& J.F. MURPHY}

Centre for Ecology and Hydrology, Winfrith Technology Centre, Winfrith Newburgh, Dorchester, Dorset, UK.

Correspondence: Ralph T. Clarke, CEH, Winfrith Technology Centre, Winfrith Newburgh, Dorchester, Dorset, DT2 8ZD, UK

E-mail address: rtc@,ceh.ac.uk

Keywords: macroinvertebrates, RIVPACS, expected probabilities, replicate sampling, statistical power, stress 


\section{SUMMARY}

1. The overall aim in freshwater bioassessment is to use biological methods, metrics and forms of indices which are precise, in that they give repeatable results between replicate samples, but which are also sensitive to changes in environmental impacts and stresses. We investigated the effects of excluding taxa with site-specific RIVPACS-type model expected probabilities less than (or equal to) a threshold $P_{t}(0.0,0.1,0.2, \ldots, 0.9)$ on the value, precision and power to detect biological effects of environmental stress using the observed to expected ratios $(\mathrm{O} / \mathrm{E})$ of biotic indices used to assess the ecological status of UK river sites.

2. Amongst the 614 high quality GB RIVPACS reference sites, excluding taxa with low expected probabilities of occurrence gave less total variation (i.e. lower SD) in the estimates $\mathrm{O} / \mathrm{E}$ for number of taxa $\left(\mathrm{O} / \mathrm{E}_{\mathrm{TAXA}}\right)$ and the Average Score Per Taxon $\left(\mathrm{O} / \mathrm{E}_{\mathrm{ASPT}}\right)$.

3. A separate analysis of a replicated sampling study of sites from a wide range of physical types and qualities found that sampling variances in $\mathrm{O} / \mathrm{E}$ for reference condition sites decreased as more locally-rare taxa were excluded (but only up to $P_{t}=0.5$ for $\mathrm{O} / \mathrm{E}_{\mathrm{ASPT}}$ ). However, for moderately impacted and poor quality sites, estimates of both $\mathrm{O} / \mathrm{E}_{\mathrm{TAXA}}$ and $\mathrm{O} / \mathrm{E}_{\mathrm{ASPT}}$ based on all $\left(P_{t}=0.0\right)$, or most taxa (i.e. $\left.P_{t} \leq 0.3\right)$ had lower sampling variances and were more precise.

4. Within a very large independent set of test sites with a wide range of perceived levels of environmental stress, increasing the threshold $P_{t}$ led to systematic differences in the estimates of both $\mathrm{O} / \mathrm{E}$. Compared to using all taxa, high thresholds $(\geq 0.5)$ gave lower $\mathrm{O} / \mathrm{E}$ values for very high quality sites with $\mathrm{O} / \mathrm{E}>1$ and higher values for moderate and poor quality sites (with the exception of $\mathrm{O} / \mathrm{E}_{\mathrm{ASPT}}$ for the most severely stressed sites).

5. Accuracy and statistical power to detect environmental stress (measured by the percentage of stressed sites with $\mathrm{O} / \mathrm{E}$ below the lower 10-percentile value for reference sites) was very similar using $\mathrm{O} / \mathrm{E}_{\mathrm{TAXA}}$ for $P_{t}$ up to 0.7 . Using $\mathrm{O} / \mathrm{E}_{\mathrm{ASPT}}$, power to detect overall general stress decreased slower as $P_{t}$ was increased; the rate of fall in power was slightly faster when restricted to sites subject to moderate or severe stress from organic inputs.

6. Taxa which are more sensitive to (organic) stresses (i.e. have high BMWP scores) tend to be naturally less widespread (i.e. amongst reference sites) and thus were found to have considerably lower average site-specific expected probabilities; this may explain why the use of higher thresholds $P_{t}$ can exclude more such sensitive taxa and lead to under-estimation of the extent of impacts.

7. The standard UK RIVPACS sampling and sample processing procedures aim to identify all taxa with a sample. This may lead to a longer distribution tail of rarer (low probability) taxa than sampling methods based on a fixed count sub-sample and influence the practical effects of excluding rare taxa with low expected probabilities from bioassessments. 


\section{Introduction}

Empirical predictive models were first applied to the bioassessment of freshwater quality by researchers in the UK during the development of the River Invertebrate Prediction and Classification System (RIVPACS) (Wright et al., 1984; Moss et al., 1987; Wright, 1995). The RIVPACS approach is now well established in the UK (Wright et al., 2000), Australia (Smith et al., 1999), Canada (Reynoldson et al., 2000), Sweden (Johnson, 2003) and the Czech Republic (Zahrádková et al., 2000), and is currently being developed and evaluated for other regions (Joy \& Death, 2003; Ostermiller \& Hawkins, 2004, Van Sickle et al., 2005).

There are a number of steps involved in developing a regional RIVPACS model (Clarke et al., 2003, Bailey et al., 2004). First a comprehensive set of reference biological samples from high quality, minimally disturbed sites is collected to represent the full range of physical stream types present in the region, in terms of variation both between and within catchments. The samples are collected and processed using standard protocols. Some form of cluster analysis is then used to classify the samples into groups based on the similarity of their recorded community composition. The relationships between the measured environmental features and biological characteristics of the reference site groups are defined by multiple discriminant analysis (MDA). The derived discriminant functions are used to estimate the probability of membership to each classification group for any site based on its values for the same environmental features. The probabilities of the test site belonging to each classification group are combined with the proportional occurrence of each taxon amongst the reference sites in each of the groups to calculate (as weighted averages) the expected probabilities of capture for each taxon at the test site, if it was also of reference high quality and minimally disturbed (Clarke et al., 2003). The observed fauna at the test site (collected using the same standardised procedures) can then be compared with the expected fauna to derive a bioassessment of the ecological status of the site.

Although this comparison of observed and expected fauna can be done in a variety of ways (Clarke et al.,1996), most assessments around the world based on RIVPACS-type predictive models (cited above) concentrate on the use of the ratio of the observed $(\mathrm{O})$ to site-specific expected (E) number of taxa at the site (denoted O/E $\mathrm{E}_{\mathrm{TAXA}}$ ). However, in the UK, national river assessments by government environment agencies using macroinvertebrates are currently based on both $\mathrm{O} / \mathrm{E}_{\mathrm{TAXA}}$ and the ratio (denoted $\mathrm{O} / \mathrm{E}_{\mathrm{ASPT}}$ ) of the observed to expected values for the metric ASPT (Average Score Per Taxon) based on the BMWP (Biological Monitoring Working Party) system for scoring families (1-10) by their perceived tolerance to 
organic pollution (Armitage et al., 1983; Hemsley-Flint, 2000). The UK government agencies are working towards involving more metrics intended to measure specific types of stress to incorporate the best features of the multi-metric and multivariate predictive modelling approaches.

While the process of RIVPACS model development and testing around the world usually follows a similar generic path, individual models vary in some aspects e.g. field and laboratory procedures, taxonomic resolution, statistical classification method, and whether to exclude locally-rare taxa from the calculation of $\mathrm{O} / \mathrm{E}$ values. Quantification of the variation and errors associated with one or more of these aspects has been addressed for a number of different regional models (Moss et al., 1999; Clarke, 2000; Hawkins et al., 2000; Cao et al., 2002; Clarke et al., 2002; Ostermiller \& Hawkins, 2004).

The main topic of this paper concerns whether or not it is best to exclude taxa with low expected probabilities of occurrence at a site from its bioassessment. In particular, we investigate the effect of only including taxa which have more than a certain threshold $\left(P_{t}\right)$ of expected probability of occurrence at a site on the estimation, sampling precision and power to detect environmental stress of $\mathrm{O} / \mathrm{E}$ ratio(s) across a range of types and qualities of site.

Historically, UK RIVPACS models have included all taxa (i.e. $P_{t}=0$ ) in assessments, in the belief that the many locally rare taxa are likely to be the first to disappear as a site becomes more stressed. While this assumption has yet to be rigorously tested, there is a suggestion that excluding rare taxa can reduce the sensitivity of community-based assessments through its differential effects on sites depending on their taxa richness and abundance patterns (Cao et $a l ., 1998)$. This view is contested by others workers who argued that excluding rare taxa leads to reduced variance in model predictions and hence more confidence in the assessment of quality at a site (Hawkins et al. 2000; Marchant, 2002).

Predictive models in the Australian River Assessment Scheme (AUSRIVAS) use $P_{t}=0.5$, based on the initially untested assumption that taxa with low probabilities of occurring at a site do not contribute reliable information to the bioassessment of site condition (Smith et al. 1999; Simpson and Norris 2000). Based on a study of 234 references sites and 254 test sites (potentially impaired by past logging), Hawkins et al. (2000) found that site assessments based on using $P_{t}=0.0$ were more variable than those based on $P_{t}=0.5$ and concluded that the inclusion of more taxonomic information from such locally-rare taxa would decrease model sensitivity to deterioration in site condition. Marchant (2002) examined the effect of 
varying $P_{t}$ on the variability in $\mathrm{O} / \mathrm{E}$ for number of genera between seven sites immediately below large dams in Victoria, Australia. Because the sites were severely impacted with average $\mathrm{O} / \mathrm{E}$ of around 0.5 , all sites were classed as impacted (i.e. $\mathrm{O} / \mathrm{E}$ less than the lower 10 percentile value of 0.82 for reference sites) regardless of the threshold used, except for one site when $P_{t}=0.9$, which he took as evidence to support the use of $P_{t}=0.5$ in AUSRIVAS. However, his main analysis (see Figure 1 in Marchant (2002)) had shown that the variability in $\mathrm{O} / \mathrm{E}$ between the sites was least when all taxa were included (coefficient of variation(CV) $=6.2 \%$ for $\left.P_{t}=0\right)$, or when $P_{t}=0.1(\mathrm{CV}=8.0 \%)$, and increased with the threshold used $(\mathrm{CV}=$ $17.8 \%, 18.3 \%$ and $39.4 \%$ for $P_{t}=0.5,0.7$ and 0.9 respectively). This evidence actually provides some support for using all taxa in site assessments. Moreover, Turak and Koop (2003) examined multiple-year data from two sites in New South Wales, Australia and concluded that including all taxa (i.e. with $P_{t}=0$ ) in AUSRIVAS estimates of $\mathrm{O} / \mathrm{E}$ enhances the ability to detect differences in levels of disturbance compared to using the recommended threshold $P_{t}$ of 0.5. Johnson \& Sandin (2001) investigated the effect of threshold $\left(P_{t}\right)$ values of $0.0,0.1,0.25$ and 0.5 on the strength of the correlation between $\mathrm{O}$ and $\mathrm{E}$ values and the standard deviation (SD) of $\mathrm{O} / \mathrm{E}$ values for number of taxa with a set in reference sites in

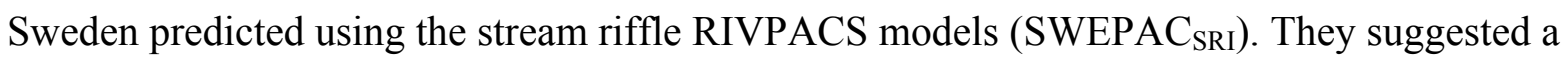
compromise threshold of 0.25 .

Recently, Ostermiller \& Hawkins (2004) concluded that it was difficult to determine what optimal $P_{t}$ value would give a precise predictive model, in terms of eliminating noise associated with very rare taxa, and at the same time a sensitive model, in terms of incorporating as much (biological response) information on the taxa-environment relationship as possible. Cao et al. (2001, p149-150) give a clear summary of the problem in terms of the two types of error in site bioassessments, namely (i) indicating a non-existing impact or overestimating an impact, and (ii) failing to detect an impact or under-estimating its size. They conclude that the inclusion or exclusion of rare taxa appears to be mainly related to (ii) in that if an assessment based on only abundant (or high probability) taxa does not detect an impact, it may be because only the rarer species have been affected (or eliminated from the site).

In our view, although low probability taxa may individually contribute little, there are often many of them, so collectively they may be very informative. The overall aim in any bioassessment is to use biological methods, metrics and forms of indices which are precise, in that they give repeatable results between replicate samples, but which are also sensitive to changes in environmental impacts and stresses. 
The choice of the optimal $P_{t}$ has not been comprehensively investigated across a range of sites with different levels of impairment. Recent studies on this issue have proved inconclusive, in terms of their relevance to RIVPACS-type models for general use, as they have generally investigated the effect of excluding rare taxa on limited datasets (Cao et al., 1998; Marchant, 2002), or on sites drawn only from reference site datasets (Johnson, 2003) or have only compared a very restricted number of $P_{t}$ values (Hawkins et al., 2000; Ostermiller \& Hawkins, 2004). In their excellent study of the impact of various aspects of a sampling methodology, Ostermiller \& Hawkins (2004) found that the standard deviation (SD) in O/E values for their reference sites was less for $P_{t}=0.5$ than for $P_{t}=0.0$ for all fixed sub-sample sizes tested, from which they concluded that models based on the use of $P_{t}=0.5$ were more precise. However, in the extreme if you base $\mathrm{O} / \mathrm{E}$ values only on those taxa which are (nearly) always found $\left(P_{t} \geq 0.9\right)$ at that type of reference site, then the observed and expected number of taxa for the reference sites must be almost identical so that $\mathrm{O} / \mathrm{E}$ values will hardly vary about unity. Although sampling precision and repeatability for high quality sites is obviously important to minimise the occurrence of type 1 errors, the detection and estimation of the extent of impacts will depend on the (potentially different) sampling precision in $\mathrm{O} / \mathrm{E}$ ratios for poorer quality sites and the extent to which they differ from $\mathrm{O} / \mathrm{E}$ values for reference sites.

We assessed the effect of varying $P_{t}$ on the values, precision and accuracy of RIVPACS model estimates for both $\mathrm{O} / \mathrm{E}_{\mathrm{TAXA}}$ and $\mathrm{O} / \mathrm{E}_{\mathrm{ASPT}}$. In particular the effect of $P_{t}$ on four factors was assessed: (i) overall variation (SD) in O/E for RIVPACS reference sites, (ii) replicate sampling SD in $\mathrm{O} / \mathrm{E}$ across a wide range of qualities of site and (iii) systematic differences in the value of $\mathrm{O} / \mathrm{E}$ for sites from a range of water qualities and stream types, and most importantly (iv) the resulting statistical power to detect biological impacts at independently assessed environmentally stressed sites.

\section{Methods}

Relevant aspects of the UK RIVPACS reference sites, sampling and model development methodology

In the UK, there is currently a single RIVPACS prediction and site assessment module for the whole of mainland Great Britain (GB) based on 614 reference sites (Moss, 2000); although separate modules have recently been developed for Northern Ireland and the Scottish islands. 
All reference sites have been sampled using standard RIVPACS sampling and sample processing procedures (Wright et al., 1984; Environment Agency, 1999). This involves a 3 minute active kick sample with a pond net plus a 1-min hand search for taxa likely to be missed in the kick sample e.g. those adhered to large stones and bedrock. All habitats within the site are sampled in proportion to their occurrence. In the laboratory, the entire sample is carefully sorted through for macroinvertebrates, with the aim of identifying and recording all of the taxa within the sample (but using where appropriate varying degrees of sub-sampling $(1 / 2,1 / 4,1 / 8$ sample, etc) purely to estimate the abundance of very common taxa) (Wright, 2000). The procedure of sorting through the whole sample within the aim of finding all of the taxa present is an important difference in the RIVPACS method compared to some other methods which only identify a "random" sub-sample and/or a random fixed number of individuals in a sample. This could have repercussions for the effect of excluding locally-rare taxa from site assessments and is discussed further below.

Each reference site was sampled once in each of spring (March - May), summer (June August) and autumn (September - November). A single classification of the reference sites into groups was derived for the GB module based on the best available biological information for each site, namely the three seasons combined fauna based on presence-absence of species and $\log$ abundance category of families. The MDA functions can then be used to derive both site- and season-specific predictions of the fauna to be expected for any single season sample or any combined season (e.g. spring+autumn, or spring+summer+autumn) sample, which can then be compared with the corresponding observed sample fauna for the same season(s) from any site.

Clarke et al. (1996) pointed out that the reference sites used in any RIVPACS-type model will not all be of the same biological quality. In practice, they usually represent the top class of sites, and are likely to be very variable in quality. The variation and distribution of the sample $\mathrm{O} / \mathrm{E}$ values for a set of reference sites is therefore due to both sampling variation and methodological errors, but also due to real variation in their true quality - albeit unknown. Therefore, some variation in $\mathrm{O} / \mathrm{E}$ values amongst references sites is always to be expected.

\section{BAMS study sites used to estimate sampling variation in $O / E$}

The analysis of replicate sampling variation was based on the 16 sites used by Clarke et al. (2002) to assess patterns of sampling variation in BMWP-based indices. These study sites 
were selected from a listing of over 5000 sites sampled during the 1990 national river quality survey (RQS) throughout England and Wales. Based on their environmental characteristics, the study sites were selected from four site groups (Table 1a), chosen to encompass the four major site divisions and site types within the RIVPACS II hierarchical classification (Wright, 1995). Next, within each of the four site groups, one study site was selected at random from the list of RQS sites in each of the four quality grades (Table 1b), giving a total of 16 sites, referred to as the BAMS (Biological Assessment Methods Study) sites,

Each BAMS site was sampled in each of the three RIVPACS seasons using the standard RIVPACS sampling procedures. On each sampling occasion and at each site, three macroinvertebrate samples were collected, the first and third were taken by an Institute of Freshwater Ecology (now CEH) biologist and the second by a local Government environment agency biologist. Care was taken to minimise the possibility of re-sampling the same locations within the site in order to avoid progressive depletion of the fauna. At any given site, the same biologists took the samples in each of the three seasons, but the personnel varied between sites and regions. The macroinvertebrate samples were all sorted and identified by experienced IFE/CEH biologists using the standardised RIVPACS protocols (Wright et al., 1984; Environment Agency, 1999). Three people also made independent estimates of the RIVPACS environmental predictor variables and hence expected fauna at each site - leading to three independent estimates of $\mathrm{O} / \mathrm{E}$ values.

\section{GQA (General Quality Assessment) sites and their anthropogenic stresses}

The third sets of sites involved in the analyses reported here (in addition to the 614 RIVPACS reference sites and the 16 BAMS sites) are 5752 sites from the Environment Agency (EA)'s General Quality Assessment (GQA) national survey of river sites throughout England and Wales in 1995 (Murphy \& Davy-Bowker, 2005). Samples were taken in both spring and autumn. The results of our analyses are presented for spring samples, but similar results were obtained for autumn samples.

This large dataset was used to test for systematic dependence of $\mathrm{O} / \mathrm{E}$ on the threshold probability $P_{t}$. and, most importantly, to assess the effect of the choice of $P_{t}$ on the statistical power of the resulting $\mathrm{O} /$ Es to detect the biological impacts of anthropogenic stress operating at the site. The severity of each of 12 major types of anthropogenic stress acting on each site was recorded by local EA biologists from their detailed knowledge of sites and catchments in 
their area (Table 2) (Murphy \& Davy-Bowker, 2005). EA catchment management plans were also consulted by biologists where more information was needed. We derived an overall measure of stress intensity by dividing the sum (S) of the levels of the 12 stress types into four classes (Table 2).

\section{Calculating O/E for different threshold expected probabilities}

If taxon $i$ (species or family) occurs in $r_{i j}$ of the $n_{j}$ reference sites in group $j$, then the RIVPACS expected probability, $p_{i}$, of finding a particular taxon $i$ at a particular test site, if the site is unstressed, is estimated from the proportion $q_{i j}=r_{i j} / n_{j}$ of reference sites in each group $j$ with taxon $i$ present, weighted by the test site's probabilities $G_{j}$ of belonging to each group j, namely (Clarke et al., 2003):

$$
p_{i}=\sum_{j} G_{j} q_{i j}
$$

The expected number of taxa $\left(E_{T}\right)$ for a site is simply the sum of the site-specific expected probabilities of the individual taxa, namely:

$$
E_{T}=\sum_{i} p_{i}
$$

The observed value $\left(O_{A}\right)$ of ASPT for a site is calculated as the sum $\left(O_{S}\right)$ of the individual BMWP scores $\left(B_{i}\right)$ of the $O_{\mathrm{T}}$ BMWP-scoring taxa present, divided by $O_{T}$. Calculation of the expected value, $E_{A}$, of ASPT is more complex as it is a ratio of variables, but a very good approximation (from Clarke et al., 1996) is given by:

$$
E_{A}=E_{S} / E_{T}+v_{T T} E_{S} / E_{T}^{3}-v_{S T} / E_{T}^{2}
$$

where $E_{S}=\sum_{i} B_{i} p_{i}=$ expected value of total BMWP score,

$$
v_{T T}=\sum_{i} p_{i}\left(1-p_{i}\right) \text { and } v_{S T}=\sum_{i} B_{i} p_{i}\left(1-p_{i}\right)
$$

(Note: Equation (2) is the same as equation (11) in Clarke et al. (1996) except that the last term $v_{S T} / E_{T}^{2}$ should be subtracted not added; the term is minor, the effect is negligible and importantly, the correct formula has always been used in all versions of RIVPACS software code).

The $\mathrm{O} / \mathrm{E}$ ratios for number of taxa and ASPT are then given by: 
$O / E_{T A X A}=O_{T} / E_{T}$ and $O / E_{A S P T}=O_{A} / E_{A}$

When the $\mathrm{O} / \mathrm{E}$ ratios for a site are to be based on only those taxa with site-specific expected probabilities of occurring $\left\{p_{i}\right\}$ greater than a threshold probability $P_{t}$, then only those taxa for which $p_{i}>P_{t}$ are included in the calculation of both the observed $(O)$ and expected $(E)$ and hence $O / E$ values of each metric; in our case, 'number of taxa' and ASPT based on equations (1)-(3). In our study, the effect of a wide range of threshold probabilities was assessed, using $P_{t}=0.0,0.1,0.2,0.3,0.4,0.5,0.6,0.7,0.8,0.9$, where $P_{t}=0.0$ is equivalent to including all of the taxa in the calculation of $\mathrm{O} / \mathrm{E}$ ratios and site assessments.

\section{Results}

Illustration of the potential effect of using different thresholds

To illustrate the effect of using different threshold probabilities on $\mathrm{O} / \mathrm{E}$ values, a detailed comparison of the observed and expected fauna was made for a replicate sample from one of the moderately impacted BAMS sites (Table 3). In general, as more taxa are excluded so both the observed and expected number of taxa can only decrease, but their ratio $O / E_{T A X A}$ can, in theory, go up or down. In this example $\mathrm{O} / \mathrm{E}_{\mathrm{TAX}}$ increased as the threshold probability for exclusion was increased from 0.0 to 0.9 . This was also true for the two other replicate spring samples from this site (Fig. 1).

\section{Effect of threshold on distribution and SD of O/E values for RIVPACS reference sites}

We assessed the effect of using each threshold probability on the distribution of $\mathrm{O} / \mathrm{E}$ values for the 614 RIVPACS reference sites for mainland Great Britain (Table 4, Fig. 2). Results are shown for spring samples, but similar patterns were obtained with samples from other seasons. The overall mean value of $\mathrm{O} / \mathrm{E}_{\mathrm{TAX}}$ was always around one, but the distribution became less variable as the threshold was increased (Figure 2a). In particular, the standard deviation (SD) started to decline considerably once the threshold $P_{t}$ was above 0.2 or 0.3 (Table 4(a)). Hawkins et al. (2000) and Ostermiller \& Hawkins (2004) also found smaller overall $\mathrm{SD}$ in the $\mathrm{O} / \mathrm{E}$ values of reference sites when based on a threshold probability of 0.5 compared to when including all taxa $\left(P_{t}=0.0\right)$. However, as seen in Figure 2a, the biggest cause of the reduction in overall SD is that excluding taxa expected to be locally rarer reduces the frequency and extent of high $\mathrm{O} / \mathrm{E}$ values well above 1 . In the extreme, with a threshold of 
0.9 , all of the observed taxa must have at least a $90 \%$ expected probability of occurring, so it is mathematically impossible to get an $\mathrm{O} / \mathrm{E}_{\mathrm{TAXA}}$ value greater than $1 / 0.9$, namely 1.111 . The median (but not mean) value of $\mathrm{O} / \mathrm{E}_{\mathrm{TAX}}$ was slightly above unity for high values of $P_{t}$ (Figure 2(a)).

A similar pattern was observed for the distribution of O/E for ASPT for the same RIVPACS reference sites (Fig. 2b). Again, the SD changed very little up to a threshold of 0.3 , but thereafter decreased (until $P_{t}=0.9$ ) (Table 4(a)). However, unlike for $\mathrm{O} / \mathrm{E}_{\mathrm{TAXA}}$, at high thresholds, there is increased likelihood of occasional very high or low values of $\mathrm{O} / \mathrm{E}_{\mathrm{ASPT}}$, because the ASPT metric is an average (score per taxon present) and its value can change dramatically and erratically when dependent on the chance presence-absence of only a few taxa.

\section{Effect of threshold on sampling precision of $O / E$ across a range of site qualities}

The precision of $\mathrm{O} / \mathrm{E}$ estimates based on different threshold probabilities $P_{t}$ was assessed using the BAMS sites data for which there were three replicated samples and three independent estimates of $\mathrm{O} / \mathrm{E}$ values for each of three sampling seasons across a wide range of types and qualities of river sites in the UK.

In order to summarise the replicate sampling SD robustly for each expected probability threshold $P_{t}$, the data were grouped into three quality classes according to the replicate mean value of $\mathrm{O} / \mathrm{E}_{\mathrm{TAXA}}$ (Fig. 3(a)). Using $P_{t}=0$, the sampling $\mathrm{SD}$ of $\mathrm{O} / \mathrm{E}_{\mathrm{TAXA}}$ increased with site quality (Table 5(a)); this is not unexpected as Clarke et al. (2002) found that replicate sampling SD of the observed number of taxa in a sample increased with site taxa richness. In contrast, when very high expected probability thresholds were used, sampling variability in $\mathrm{O} / \mathrm{E}_{\text {TAXA }}$ was highest at intermediate site quality For the high quality class of sites with replicate mean $\mathrm{O} / \mathrm{E}_{\mathrm{TAX}}$ greater than 0.9 , the sampling $\mathrm{SD}$ decreased as $P_{t}$ was increased, as was found previously for reference sites. The only exception was for the extreme threshold $P_{t}$ $=0.9$, but this was because the class lower limit for replicate mean $\mathrm{O} / \mathrm{E}$ was sufficiently low to encompass one of the mildly stressed sites for which $\mathrm{O} / \mathrm{E}$ was more variable when based on such a high threshold probability and thus only a few taxa. For intermediate quality mildly stressed sites with replicate mean $\mathrm{O} / \mathrm{E}_{\mathrm{TAXA}}$ in the range $0.6-0.9$, the general pattern was reversed - assessments involving all or most taxa had the lowest SD and greatest precision (Fig. 3(a)). Using high thresholds leads to only relatively few taxa being involved, which may 
or may not still be present (and counted), giving rise to more variable $\mathrm{O} / \mathrm{E}$ values. At poor quality sites with replicate mean $\mathrm{O} / \mathrm{E}_{\mathrm{TAXA}}$ less than 0.6 , all thresholds gave similar, relatively low, sampling SD in the range 0.058-0.079 (Table 5(a)). One-way ANOVA was used to estimate the overall average replicate sampling variance across all site and season combination for each threshold. The overall average replicate SD was about the same (0.0720.074 ) for expected probability thresholds up to 0.4 , but thereafter increased ("overall" column in Table 5(a)).

In similar analyses for $\mathrm{O} / \mathrm{E}_{\mathrm{ASPT}}$, sampling $\mathrm{SD}$ of $\mathrm{O} / \mathrm{E}_{\mathrm{ASPT}}$ for high quality sites was marginally highest for $P_{t}=0.0$ (Table 5(b), Fig 3(b)). However, at intermediate and poor quality sites with replicate mean values of $\mathrm{O} / \mathrm{E}_{\mathrm{ASPT}}$ less than 0.9 , assessments based on using either all the taxa $\left(P_{t}=0.0\right)$, or an expected probability threshold of no more than 0.3 , had the lowest sampling SD (Fig. 3(b)). All thresholds (except $P_{t}=0.9$ ) gave slightly higher sampling $\mathrm{SD}$ once replicate mean $\mathrm{O} / \mathrm{E}_{\mathrm{ASPT}}$ dropped below 0.7 , mainly because fewer taxa were involved in determining the observed ASPT. Averaged over all sites and seasons, the overall average sampling SD was about the same (0.046-0.050) for thresholds up to 0.5, but thereafter increased (Table 5(b)).

\section{Effect of threshold on value of $O / E$}

To obtain a reasonably precise estimate of any systematic differences in average value of $\mathrm{O} / \mathrm{E}$ arsing from using different thresholds, the $\mathrm{O} / \mathrm{E}$ values based on each threshold $P_{t}$ were calculated for all of the spring samples from the 5752 GQA sites. For each sample, the O/E value based on $P_{t}=0.0$ was subtracted from the $\mathrm{O} / \mathrm{E}$ based on each non-zero threshold to give the differences in $\mathrm{O} / \mathrm{E}$. The samples were then grouped into classes according to their $\mathrm{O} / \mathrm{E}$ based on $P_{t}=0.0$. The median differences in $\mathrm{O} / \mathrm{E}$ values for each threshold for each class of site are given in Figure 4.

A threshold $P_{t}$ of 0.1 gave negligible systematic difference in $\mathrm{O} / \mathrm{E}_{\mathrm{TAXA}}$ for qualities of sites except those with the very highest values when based on all taxa (Fig. 4(a)). When the value of $\mathrm{O} / \mathrm{E}_{\mathrm{TAXA}}$ based on all of the taxa was around unity (i.e. observed and expected number of taxa agree), then the median difference in $\mathrm{O} / \mathrm{E}_{\mathrm{TAXA}}$ value using any non-zero threshold was relatively small, indicating that such $\mathrm{O} / \mathrm{E}_{\mathrm{TAX}}$ values were roughly equally likely to be higher or lower than those based on all taxa (Fig. 4). However for poorer quality sites (i.e. those with $\mathrm{O} / \mathrm{E}_{\text {TAXA }}$ values $<0.9$ ), the median difference was always positive and the difference 
increased with the value of the threshold $P_{t}$, indicating that there was a systematic tendency for the estimate of $\mathrm{O} / \mathrm{E}_{\mathrm{TAXA}}$ for stressed sites to increase as more of the lowest probability taxa were excluded from the site assessments (Fig. 4). For sites with values of O/E well above unity when based on all taxa, the $\mathrm{O} / \mathrm{E}$ estimates tended to be less when based solely on the taxa with higher expected probabilities of occurrence at the sites(Fig. 4).

The pattern of systematic differences in $\mathrm{O} / \mathrm{E}_{\mathrm{ASPT}}$ resulting from increasing the threshold probability were largely similar to those for $\mathrm{O} / \mathrm{E}_{\mathrm{TAXA}}$ (Fig. 4). For both $\mathrm{O} / \mathrm{E}$ indices, the differences using any of the non-zero threshold probabilities was greatest for sites of intermediate-poor quality. However, in contrast to $\mathrm{O} / \mathrm{E}_{\mathrm{TAX}}$, values of $\mathrm{O} / \mathrm{E}_{\mathrm{ASPT}}$ for the very poorest quality sites with $\mathrm{O} / \mathrm{E}_{\mathrm{ASPT}}$ less than 0.5 did not show any systematic change with threshold $P_{t}$ (Fig. 4(b)).

Overall, our analyses show a systematic tendency for $\mathrm{O} / \mathrm{E}$ values for a site to become closer to unity as the threshold of expected probability is increased. In other words, using higher thresholds makes it more difficult (or even impossible) to obtain $\mathrm{O} / \mathrm{E}$ values far above or, more importantly, far below unity. We were concerned that these results might be an artefact due to grouping the GQA sites on the basis of their $\mathrm{O} / \mathrm{E}$ values calculated using all of the taxa (i.e. $P_{t}=0.0$ ). Therefore, the GQA sites were re-grouped into classes on the basis of their $\mathrm{O} / \mathrm{E}$ values calculated using a threshold of $P_{t}=0.5$. For each sample, the $\mathrm{O} / \mathrm{E}$ value based on $P_{t}=$ 0.5 was subtracted from the $\mathrm{O} / \mathrm{E}$ values based on each other threshold (including $P_{t}=0.0$ ) to give the differences in $\mathrm{O} / \mathrm{E}$. The patterns of median differences in $\mathrm{O} / \mathrm{E}$ values for each threshold for each class of site are shown in Fig. 5. Thresholds less than 0.5 (included $P_{t}=$ 0.0 ) show a tendency to give lower values of $\mathrm{O} / \mathrm{E}_{\mathrm{TAXA}}$ when the $\mathrm{O} / \mathrm{E}$ for $P_{t}=0.5$ is less than unity and higher values when $\mathrm{O} / \mathrm{E}$ for $P_{t}=0.5$ is greater than unity. Also $\mathrm{O} / \mathrm{E}_{\mathrm{TAXA}}$ values for thresholds greater than 0.5 showed the same pattern as before, giving values of $\mathrm{O} / \mathrm{E}$ closer to unity than those based on a threshold of $P_{t}=0.5$. For sites of intermediate quality (in the sense of having $\mathrm{O} / \mathrm{E}_{\mathrm{ASPT}}$ values for $P_{t}=0.5$ in the range $0.5-0.9$ ), thresholds less than 0.5 , on average give lower values of $\mathrm{O} / \mathrm{E}_{\mathrm{ASPT}}$, and vice versa. The median differences are less for very poor quality sites (i.e. with $\mathrm{O} / \mathrm{E}_{\mathrm{ASPT}}<0.5$ ).

Together these results indicate that increasing the expected probability threshold $P_{t}$ for taxa to be involved in the calculation of $\mathrm{O} / \mathrm{E}$ values leads to systematic changes in the estimates of O/E. Most importantly, increasing the threshold $P_{t}$ leads to a compression of the whole scale of $\mathrm{O} / \mathrm{E}$ towards unity, which may have repercussions for the ability to detect the impact of stress. 
Effect of threshold on statistical power to detect biological impacts of anthropogenic stress

We have shown that the variability in $\mathrm{O} / \mathrm{E}$ for reference sites, the sampling variation of $\mathrm{O} / \mathrm{E}$ for impacted sites and the extent of changes from unity in $\mathrm{O} / \mathrm{E}$ values are all affected by the choice of the threshold expected probability $P_{t}$. However, it is the combination and interplay of these factors which determines the statistical power to detect the biological effects of environmental and anthropogenic stress. Using a higher threshold may lead to less reduction in $\mathrm{O} / \mathrm{E}$ for stressed sites, but providing the natural variability in $\mathrm{O} / \mathrm{E}$ for high-quality reference sites (based on the same $P_{t}$ ) is lower and the sampling variability for stressed sites is not (much) greater, then using the higher threshold may provide greater statistical power to detect departure from reference conditions. An O/E value of, for example, 0.7, does not have the same interpretation in terms of extent of any biological impact for all values of $P_{t}$. We assessed the statistical power to detect impacts using each threshold $P_{t}$ using the large GQA dataset for which we had independent assessments of the intensity of anthropogenic stresses operating at each site (Table 2).

Clarke et al. (1996) suggested using some lower percentile of the distribution of O/E values for the reference sites/samples as the lower limit of O/E for which any test site would be classified as of "reference" quality class. Van Sickle et al. (2005) treated test sites as impaired if their $\mathrm{O} / \mathrm{E}$ values were outside the interval (mean $\pm 2 \mathrm{SD}$ ) determined from the $\mathrm{O} / \mathrm{E}$ for the reference samples. Ostermiller and Hawkins (2004) considered a test site as significantly different from reference if its $\mathrm{O} / \mathrm{E}$ value was outside the $10^{\text {th }}$ to $90^{\text {th }}$ percentiles of reference site $\mathrm{O} / \mathrm{E}$ values. We used the lower 10-percentile values of $\mathrm{O} / \mathrm{E}_{\mathrm{TAXA}}$ and $\mathrm{O} / \mathrm{E}_{\mathrm{ASPT}}$ for the RIVPACS GB reference sites to set the critical value for deciding whether test sites should be classified as "stressed" (lower O/E) or "reference" (higher O/E). Using this type of rule ensures that a known fixed percentage of the RIVPACS model reference sites/samples would be incorrectly classified as "impaired" (i.e. the overall type 1 error equals $10 \%$ ).

The GQA sites were classified into four stress intensity classes according to their score $S$ representing their overall loading of anthropogenic stresses (Table 2, Table 6). A GQA site was classified as "impacted" if its $\mathrm{O} / \mathrm{E}$ value based on a particular threshold $P_{t}$ was less than the critical O/E value for the reference sites based on the same $P_{t}$. Using $\mathrm{O} / \mathrm{E}_{\mathrm{TAX}}$, the statistical power to detect biological impacts among sites subject to "moderate" or "severe" 
levels of overall stress was very similar for all thresholds up to 0.7 ; although the marginally highest power occurred for $P_{t}$ equal to 0.1 or 0.2 (Table 6).

When based on $\mathrm{O} / \mathrm{E}_{\mathrm{ASPT}}$, the statistical power to detect the biological impacts of "moderate" or "severe" levels of stress was marginally highest (72\%) when all taxa were involved in the calculation of $\mathrm{O} / \mathrm{E}_{\mathrm{ASPT}}$, but only declined slowly with increasing threshold up to $P_{t}$ of 0.6 , and was lowest for $P_{t} \geq 0.7$ (Table 6). The percentage of "unstressed" GQA sites incorrectly classified as being impacted (i.e. type 1 error) was similar for all values of the threshold $P_{t}$ for both $\mathrm{O} / \mathrm{E}$ indices with the exception of higher mis-classification rates for $\mathrm{O} / \mathrm{E}_{\mathrm{ASPT}}$ based on $P_{t}=0.9$.

The ASPT metric was originally intended to provide a measure of the biological response of freshwater macroinvertebrate communities to stress resulting from organic inputs (e.g. from agriculture or effluent). Therefore, we also assessed the effect of varying $P_{t}$ on the statistical power to detect biological impacts using $\mathrm{O} / \mathrm{E}_{\mathrm{ASPT}}$ amongst the GQA classified according to their perceived level of stress from organic inputs only (Table 6). The statistical power of $\mathrm{O} / \mathrm{E}_{\mathrm{ASPT}}$ for each threshold $P_{t}$ was higher when the analysis was restricted to detecting severe levels of stress specifically from organic inputs (Table 6). Although still highest (79\%) for $P_{t}$ $=0$, statistical power of detecting severe organic input stress was similar (74-79\%) for all thresholds up to $P_{t}=0.5$.

It was encouraging to find that the percentage of sites classified as impacted on the basis of their $\mathrm{O} / \mathrm{E}$ values increased with the perceived intensity of anthropogenic stress operating at a site, as one would hope. In addition, the percentage of sites with no known significant overall stress loading (i.e. "unstressed" sites) which were mis-classified as impacted on the basis of their $\mathrm{O} / \mathrm{E}$ values was only $11-20 \%$ for both metrics based on thresholds up to 0.7 (Table 6); this is not enormously greater than the $10 \%$ type 1 error expected from reference sites/samples.

\section{Discussion}

The aim of this study was to investigate the effects of excluding taxa with low site-specific expected probabilities (based on RIVPACS-type models) on the precision and accuracy of $\mathrm{O} / \mathrm{E}$ ratios of biotic indices and on their statistical power to detect the biological impacts of anthropogenic stresses in bioassessments of the ecological status of sites. In particular, we have assessed the previously-unknown effects of changing probability threshold $P_{t}$ on 
bioassessments based on the use of the standard RIVPACS sampling and sample processing procedures, as used by the government environment agencies (and $\mathrm{CEH}$ ) throughout the UK (Environment Agency, 1999). The conclusions can be summarised as follows:

(i) Excluding taxa with low expected probabilities of occurrence results in less variation (i.e. lower $\mathrm{SD}$ ) in the $\mathrm{O} / \mathrm{E}$ estimates for reference sites;

(ii) Estimates of $\mathrm{O} / \mathrm{E}$ based on all, or most taxa (i.e. using a low $P_{t}$ ) give the lowest sampling variances at moderately impacted and poor quality sites;

(iii) Increasing the threshold probability $P_{t}$ for excluded taxa causes systematic compression of the realised $\mathrm{O} / \mathrm{E}$ scale towards unity, in that $\mathrm{O} / \mathrm{E}$ values $>1$ are on average reduced, while $\mathrm{O} / \mathrm{E}$ values $<1$ have a tendency to be higher and closer to unity.

(iv) The combined effect of these factors was that statistical power to detect the overall biological impacts of anthropogenic stresses based on $\mathrm{O} / \mathrm{E}_{\mathrm{TAXA}}$ was similar for thresholds $P_{t}$ up to 0.7 (and marginally optimum at $P_{t}$ of 0.1 or 0.2 );

(v) When based on $\mathrm{O} / \mathrm{E}_{\mathrm{ASPT}}$, power to detect impacts from both overall stress and specifically organic impacts was similarly high for $P_{t} \leq 0.5$ (and marginally optimum using $P_{t}=0$ ), although the power to detect effects of organics was greater (74-79\%).

Our results show that, at least for UK RIVPACS samples, the estimate of O/E ratio for number of taxa at moderately impacted sites has a tendency to increase as an increasing proportion of the least expected taxa are excluded from site assessments. Systematic changes in O/E with $P_{t}$ were also found by Hawkins et al. (2000), who concluded (p1466) that for their non reference quality test sites "on average $O / E_{50}$ overestimated $O / E_{0}$ with the amount of bias greatest at low $O / E_{50}$ values" $\left[O / E_{50}\right.$ and $O / E_{0}$ equate to $P_{t}=0.5$ and $\left.P_{t}=0.0\right]$. As sites become stressed so sensitive taxa will become less abundant and eventually disappear from the site and samples. The taxa with the highest RIVPACS expected probabilities of being found in a sample will generally also be the most abundant at the site (if unstressed). Therefore, on average, the taxa with relatively low site-specific expected probabilities are generally likely to disappear first from the site and our sample counts as environmental stress increases. This may be why ignoring and excluding such taxa from the calculation of $\mathrm{O} / \mathrm{E}$ ratios by using a higher threshold $P_{t}$ leads to values of $\mathrm{O} / \mathrm{E}_{\mathrm{TAX}}$ declining less from unity. This may be true as a generality, but the rate of loss of individual taxa depends on the 
tolerance to stress (or more specifically the actual type(s) of stress operating). Cao and Hawkins (2005) used field data on reference and impacted test sites to derive stress tolerance values (TV) for individual taxa which they then used to simulate "true" changes in the abundances and occurrence of individual taxa with increasing levels of stress. They found from repeated simulations of fixed count sub-samples, the true reduction in total taxa richness at a site with stress was under-estimated; this was especially true for counts of 300 or less individuals. Cao and Hawkins (2005) cleverly explained this by showing that the evenness of the (simulated) abundances of taxa at a site increased with the level of stress, so that a relative higher proportion of the taxa still present at a stressed site would be captured in a fixed count sample. However, changes in evenness of taxa abundance with stress would not have such an obvious impact on the observed sample taxa richness obtained by area- or timebased sampling methods such as RIVPACS which aim to identify and include all of the taxa in a sample. This is discussed further below.

It is less obvious why $\mathrm{O} / \mathrm{E}_{\mathrm{ASPT}}$ also tends to be higher at moderately stressed sites when based on higher expected probability thresholds. One explanation could be that the families most susceptible to organic pollution (with high BMWP scores) have, on average, much lower expected probabilities of occurrence than more tolerant families with low scores. Ignoring taxa with low expected probabilities would then tend to ignore the loss of these sensitive families and lead to higher estimates of $\mathrm{O} / \mathrm{E}_{\mathrm{ASPT}}$. To assess this, the BMWP families were assigned to three classes $(1-4,5-7,8-10)$ based on their BMWP score (1-10). Zero (i.e. to three decimal places) expected probabilities were excluded from the subsequent analyses because some families are naturally restricted to particular types of stream and hence naturally excluded from a large proportion of the sites. In addition, only families with nonzero expected probabilities are involved in the calculation of the expected ASPT for a site. Including the large numbers of zero values would distort the frequency distributions. In the first approach the average expected probability of occurrence $\left(\bar{p}_{i}\right)$ of each individual family $i$ across the 5752 GQA sites was calculated and then the (boxplot) distributions of the $\bar{p}_{i}$ for families within each BMWP class were compared (Fig. 6). The median of the $\bar{p}_{i}$ for highscoring (8-10) families was only 0.13 , much lower than the median of 0.46 for the lowscoring organic-stress-tolerant families (Incidentally, not excluding zero expected probabilities leads to a lower median $\bar{p}_{i}$ of 0.07 for the $8-10$ scoring families and no change (to 2 d.p.) in the median for 1-4 scoring families). A second approach was based on 
comparing the frequency distribution within the same dataset of all non-zero expected probabilities of occurrence for all families within each BMWP class. Within each class of BMWP score, the percentages of all non-zero values of expected probability occurring in each of four classes of expected probability $(<0.2,0.2-0.5,0.5-0.8,>0.8)$ were calculated and compared (Table 7). For pollution sensitive families (BMWP scoring 8-10), 57\% of all nonzero expected probabilities are less than 0.2 , compared to only $27 \%$ for pollution tolerant families (BMWP scoring 1-4). At the other extreme, only 5\% of the expected probabilities for pollution sensitive families were greater than 0.8 , compared to $35 \%$ for the most tolerant class of families (Table 7). Similar patterns in the expected probabilities were obtained when the analysis was based on the RIVPACS reference sites.

It is clear that the families with high BMWP scores, considered to be the most sensitive to organic stress, do tend to have far lower expected probabilities of occurrence than the pollution tolerant families with lower BMWP scores. The effect of this naturally occurring phenomenon is that site bioassessments involving $\mathrm{O} / \mathrm{E}_{\mathrm{ASPT}}$ which exclude all families with low site-specific expected probabilities tend to ignore the loss of these sensitive families and hence, give values of $\mathrm{O} / \mathrm{E}_{\mathrm{ASPT}}$ which deviate less from reference. This effect is greatest at moderately stressed sites because, at very poor quality sites with $\mathrm{O} / \mathrm{E}_{\mathrm{ASPT}}$ less than 0.5 , most of the families still present and found must be low scoring families, which generally have relative high expected probabilities and thus are much less affected by the exclusion of families with low site-specific expected probabilities. Similar effects of excluding taxa with low expected probabilities may occur in other $\mathrm{O} / \mathrm{E}$ type indices based on other metrics including those designed to measure specific types of stress.

One possible explanation for the difference between our conclusions and those of some other studies (Hawkins et al., 2000; Ostermiller \& Hawkins, 2004) on the perceived value of excluding taxa with low site-specific expected probabilities could be the sampling method and, perhaps more importantly, the sample processing procedures used. In the UK RIVPACS standardised procedures (Environment Agency, 1999), a 3 minute active kick sample with a pond net of all habitats in proportion to their estimated occurrence is supplemented by a 1min hand search for taxa likely to be missed in the kick sample; this will extend the sample taxa list and generally add less abundant taxa. Then in the laboratory, the whole sample is carefully sorted with the aim of finding all of the taxa in the sample. In contrast, most other studies of the factors influencing bioassessment accuracy have been based on sampling protocols which involve sub-sampling, identifying and counting a 'random' fixed number of 
individuals from the field sample. The AUSRIVAS procedure involves taking a random subsample and counting 200 individuals regardless of the total number of individuals in the field sample (Simpson \& Norris, 2000). In their study, Ostermiller and Hawkins (2004) used fixed counts of random sub-samples of 50,100, .., 450 individuals. The abundance frequency distributions of such random fixed count sub-samples are likely to have shorter tails (i.e. include proportionally fewer rare taxa present in low numbers) than the distributions obtained by searching through the whole sample to try to find all of the taxa present. One way to assess this idea would be to compare sampling/processing protocols in terms of the relative frequencies of rare taxa in the sample counts (akin to the study of Cao and Hawkins (2005)). With RIVPACS-type models, the percentage of all (non-zero) expected probabilities which are less than some small value could be calculated. For example, for the UK RIVPACS sampling protocol, $42 \%$ of all non-zero (to 3 d.p.) RIVPACS expected probabilities of occurrence are less than 0.2 (Table 7). We suggest that RIVPACS-type models based on sampling methods involving random sub-sampling of a fixed number of individuals are likely to contain a lower equivalent percentage of low expected probabilities because they tend to include less of the locally-rare taxa. In an analysis of 7-20 yr surber sample surveys of benthic macroinvertebrates from 10 sites, Resh et al. (2005) found that 17-33\% of taxa were 'rare' in that they only incurred in one year at any particular site. The abundance frequency distribution (and more obviously, taxa richness) for a site, the field sample from it and the subsequent laboratory (sub-)count can be quite different - this could have implications for metric calculation and biases in estimates of changes in $\mathrm{O} / \mathrm{E}$ with stress.

This study has highlighted that the choice of expected probability threshold $P_{t}$ influences both the variability and effective scaling of $\mathrm{O} / \mathrm{E}$ indices above and below unity. Therefore $\mathrm{O} / \mathrm{E}$ indices based on different thresholds need to be treated as separate indices with different effective scales from the point of view of setting appropriate critical values of $\mathrm{O} / \mathrm{E}$ as quality or ecological status class boundaries. You need to compare like with like.

Finally, for UK RIVPACS, using a threshold expected probability $P_{t}$ for exclusion of between 0.0 and 0.2 appears to provide the best overall compromise solution and marginally highest statistical power to detect impacts; although power was very similar for thresholds up to 0.5 . Moreover, our analyses provide no support for switching the standard assessment of river sites based on the UK RIVPACS model and UK RIVPACS sampling procedures from the current approach of basing $\mathrm{O} / \mathrm{E}$ values on all of the taxa (i.e. $P_{t}=0$ ) to a system based on only involving taxa with site-specific expected probabilities of 0.5 or more. 


\section{Acknowledgements}

The 1995 General Quality Assessment (GQA) data was provided by the Environment Agency of England and Wales. This research was funded by the UK Natural Environment Research Council through its Centre for Ecology and Hydrology. We would like to thank the referees, John Van Sickle and Yong Cao, who provided very insightful criticisms and comments which helped improve our paper.

\section{References}

Armitage P.D., Moss D., Wright J.F. \& Furse M.T. (1983) The performance of a new biological water quality score system based on macroinvertebrates over a wide range of unpolluted running-water sites. Water Research, 17, 333-347.

Bailey R.C., Norris R.H. \& Reynoldson T.B. (2004) Bioassessment of freshwater ecosystems using the reference condition approach. Kluwer Academic Publishers, Boston.

Cao, Y., Williams, D.D. \& Williams N.E. (1998) How important are rare species in aquatic community ecology and bioassessment? Limnology and Oceanography 43, 1403-1409.

Cao Y., Larsen D.P. \& Thorne R. St-J. (2001) Rare species in multivariate analysis for bioassessment: some considerations. Journal of the North American Benthological Society 20, 144-153.

Cao Y., Larsen D.P., Hughes R.M., Angermeier P. \& Patton T. (2002) Sampling efforts affect multivariate comparisons of stream assemblages. Journal of the North American Benthological Society 21, 707-714.

Cao Y. \& Hawkins C.P. (2005) Simulating biological impairment to evaluate the accuracy of ecological indicators. Journal of Applied Ecology, 42, 954-965.

Clarke R.T. (2000) Uncertainty in estimates of river quality based on RIVPACS. In: Assessing the biological quality of fresh waters: RIVPACS and other techniques. (eds J.F.Wright, D.W. Sutcliffe \& M.T. Furse), pp 39-54. Freshwater Biological Association, Ambleside. 
Clarke R.T., Furse M.T., Wright J.F. \& Moss D. (1996) Derivation of a biological quality index for river sites: comparison of the observed with the expected fauna. Journal of Applied Statistics, 23, 311-332.

Clarke R.T., Furse M.T., Gunn R.J.M., Winder J.M. \& Wright J.F. (2002) Sampling variation in macroinvertebrate data and implications for river quality indices. Freshwater Biology 47, $1735-1751$.

Clarke R.T., Wright J.F. \& Furse M.T. (2003) RIVPACS models for predicting the expected macroinvertebrate fauna and assessing the ecological quality of rivers. Ecological Modelling 160, 219-233.

Council of the European Communities (2000) Directive 2000/60/EC of the European Parliament and of the Council of 23 October 2000 establishing a framework for Community action in the field of water policy. Official Journal of the European Communities L327, 172 .

Environment Agency (1999) Procedure for collecting and analysing macroinvertebrate samples BT001 (version 2.0). Environment Agency, Bristol, UK.

Hawkins C.P., Norris R.H., Hogue J.N. \& Feminella J.W. (2000) Development and evaluation of predictive models for measuring the biological integrity of streams. Ecological Applications 10, 1456-1477.

Hemsley-Flint B. (2000) Classification of the biological quality of rivers in England and Wales. In: Assessing the biological quality of freshwaters: RIVPACS and similar techniques (Eds J.F. Wright, D.W. Sutcliffe \& M.T. Furse), pp 55-69. Freshwater Biological Association, Cumbria, UK.

Johnson R.K. \& Sandin L. (2001) Development of a prediction and classification system for lake (littoral, SWEPAC $C_{L L I}$ ) and stream (riffle $S W E P A C_{S R I}$ ) macroinvertebrate communities. Rapport 2001:23 Department of Environment Assessment, Swedish Univeristy of Agricultural Sciences, Uppsala.

Johnson R.K. (2003) Development of a prediction system for lake stony-bottom littoral macroinvertebrate communities. Archiv für Hydrobiologie 158, 517-540.

Joy M.K. \& Death R.G. (2003) Biological assessment of rivers in the Manawatu-Wanganui region of New Zealand using a predicative macroinvertebrate model. New Zealand Journal of Marine and Freshwater Research 37, 367-379. 
Marchant R. (2002) Do rare species have any place in multivariate analysis for bioassessment? Journal of the North American Benthological Society 21, 311-313.

Moss D., Wright J.F., Furse M.T. \& Clarke R.T. (1999) A comparison of alternative techniques for the prediction of the fauna of running water sites in Great Britain. Freshwater Biology 41, 167-181.

Moss D., Furse M.T., Wright J.F. \& Armitage P.D. (1987) The prediction of the macroinvertebrate fauna of unpolluted running-water sites in Great Britain using environmental variables. Freshwater Biology 17, 41-52.

Moss D. (2000) Evolution of statistical methods in RIVPACS. In: Assessing the biological quality of freshwaters: RIVPACS and similar techniques (Eds J.F. Wright, D.W. Sutcliffe \& M.T. Furse), pp 25-37. Freshwater Biological Association, Cumbria, UK.

Murphy, J.F. \& Davy-Bowker, J. (2005). Spatial structure in lotic macroinvertebrate communities in England and Wales: relationship with physical, chemical and anthropogenic stress variables. Hydrobiologia, 534, 151-164.

Ostermiller J.D. \& Hawkins C.P. (2004) Effects of sampling error on bioassessments of stream ecosystems: application to RIVPACS-type models. Journal of the North American Benthological Society 23, 363-382.

Resh, V.H., Beche, L.A. \& McElravy, E.P. (2005). How common are rare taxa in long-term benthic macroinvertebrate surveys? Journal of the North American Benthological Society 24, 976-989.

Reynoldson T.B., Day K.E. \& Pascoe T. (2000) The development of the BEAST: a predictive approach for assessing sediment quality in the North American Great Lakes. In: Assessing the biological quality of freshwaters: RIVPACS and similar techniques (Eds J.F. Wright, D.W. Sutcliffe \& M.T. Furse), pp 165-180. Freshwater Biological Association, Cumbria, UK.

Simpson J.C. \& Norris R.H. (2000) Biological assessment of river quality: development of AusRivAS models and outputs. In: Assessing the biological quality of freshwaters: RIVPACS and similar techniques (Eds J.F. Wright, D.W. Sutcliffe \& M.T. Furse), pp 165-180. Freshwater Biological Association, Cumbria, UK.

Smith M.J., Kay W.R., Edward D.H.D, Papas P.J., Richardson K. ST-J, Simpson J.C., Pinder A.M., Cale D.J., Horwitz P.H., Davies J.A., Yung F.H., Norris R.H. \& Halse S.A. (1999) 
AusRivAS: using macroinvertebrates to assess ecological condition of rivers in Western Australia. Freshwater Biology 41, 269-282.

Turak E.\& Koop, K. (2003) Use of rare macroinvertebrate taxa and multiple-year data to detect low-level impacts in rivers. Aquatic Ecosystem Health \& Management 6,167-175.

Van Sickle J., Hawkins C.P., Larsen D.P. \& Herlihy A.T. (2005) A null model for the expected macroinvertebrate assemblage in streams. Journal of the North American Benthological Society 24, 178-191.

Wright J.F. (2000) An introduction to RIVPACS. In: Assessing the biological quality of freshwaters: RIVPACS and similar techniques (Eds J.F. Wright, D.W. Sutcliffe \& M.T. Furse), pp 1-24. Freshwater Biological Association, Cumbria, UK.

Wright J.F. (1995) Development and use of a system for predicting macroinvertebrates in flowing water. Australian Journal of Ecology 20, 181-197.

Wright J.F., Moss D., Armitage P.D. \& Furse M.T. (1984) A preliminary classification of running water sites in Great Britain based on macro-invertebrate species and prediction of community type using environmental data. Freshwater Biology 14, 221-256.

Wright J.F., Sutcliffe D.W \& Furse M.T. (2000) Assessing the Biological Quality of Fresh waters: RIVPACS and other Techniques. Freshwater Biological Association, Cumbria, UK.

Zahrádková S., Kokeš J., Hodovský J., Vojtí̌ková D., Scheibová D., Pořízková Y., Schenková J. \& Helešic J. (2000) Prediction system PERLA. In: Limnologie na přelomu tisíciletí. Sborník referátů XII. limnologické conference ( Ed Rulík M.), pp. 260-264. Univerzita Palackého Olomouci, Czech Republic. 
Table 1 Characteristics of the stratified random selection of BAMS sites in terms of (a) RIVPACS site group and (b) ecological quality grades as defined by the range of $\mathrm{O} / \mathrm{E}$ values in the previous national river quality survey.

(a)

\begin{tabular}{ccccc}
\hline & \multicolumn{4}{c}{ RIVPACS site group } \\
\cline { 2 - 5 } $\begin{array}{c}\text { Mean value of } \\
\text { environmental variable }\end{array}$ & $3 \mathrm{a}$ & $5 \mathrm{~b}$ & $8 \mathrm{a}$ & $9 \mathrm{~b}$ \\
\hline Distance from source (km) & 15.3 & 8.2 & 11.3 & 33.0 \\
Width (m) & 7.5 & 4.8 & 4.8 & 13.1 \\
Depth (cm) & 19.8 & 21.7 & 32.5 & 77.5 \\
Altitude (m) & 74 & 40 & 40 & 5 \\
Alkalinity (mg 1 - $\left.^{-1} \mathrm{CaCO}_{3}\right)$ & 81 & 153 & 229 & 170 \\
Predominant substratum & cobbles/pebbles & gravel & gravel/sand & silt \\
Regions of England and & SW, NE, & central south + & east Wales to East & SE + East \\
Wales & Wales & midlands & $\begin{array}{c}\text { Anglia + southern } \\
\text { chalk streams }\end{array}$ & Anglia \\
\hline
\end{tabular}

(b)

\begin{tabular}{|c|c|c|c|c|}
\hline \multirow[b]{2}{*}{$\begin{array}{l}\text { Range of O/E values } \\
\text { based on: }\end{array}$} & \multicolumn{4}{|c|}{ quality grade } \\
\hline & $\begin{array}{c}\text { A } \\
\text { "best" }\end{array}$ & B & $\mathrm{C}$ & $\begin{array}{c}\text { D } \\
\text { "worst" }\end{array}$ \\
\hline number of taxa & $0.94-1.06$ & $0.64-0.72$ & $0.41-0.53$ & $<0.30$ \\
\hline ASPT & $0.97-1.03$ & $0.80-0.85$ & $0.68-0.74$ & $<0.60$ \\
\hline
\end{tabular}

Table 2 Twelve types of anthropogenic stress estimated at each of 5752 GQA sites and the derived measure of overall stress intensity for each site. The level (0-3) of each stress type was recorded for each site $(0=$ no stress, $1=$ light, $2=$ moderate, $3=$ severe stress $)$.

\begin{tabular}{lll}
\hline Organic input & Acidification & Agricultural chemical inputs \\
Reduced discharge & Canalisation & Riparian habitat modifications \\
Sedimentation & Urban run-off & Industrial discharge and run-off \\
Intensive arablisation & Consolidated banks & Excessive instream plant growth
\end{tabular}

Overall stress intensity based on categories of the sum (S) of the levels of all stress types

$\begin{array}{ll}\text { Unstressed } & \mathrm{S}=0 \\ \text { Light } & \mathrm{S}=1-2 \\ \text { Moderate } & \mathrm{S}=3-5 \\ \text { Severe } & \mathrm{S}=>5\end{array}$


Table 3 Comparison of the observed and expected BMWP families for a replicate sample taken in spring from the BAMS site at Swarkestone on Cuttle Brook, together with the effect of using various thresholds probabilities $P_{t}$ on $\mathrm{O} / \mathrm{E}_{\mathrm{TAXA}}$. BMWP families arranged in decreasing order of expected probability of capture $\left(p_{i}\right)$.

\begin{tabular}{|c|c|c|c|c|c|c|c|c|c|c|c|}
\hline \multicolumn{3}{|l|}{ BMWP Family } & Observed & $p_{i}$ & & \multicolumn{3}{|c|}{ BMWP Family } & $\mathrm{Ob}$ & rved & $p_{i}$ \\
\hline \multicolumn{3}{|l|}{ Chironomidae } & $*$ & 1.000 & & \multicolumn{5}{|c|}{ Piscicolidae } & 0.286 \\
\hline \multicolumn{3}{|l|}{ Oligochaeta } & $*$ & 1.000 & & \multicolumn{5}{|c|}{ Goeridae } & 0.273 \\
\hline \multicolumn{3}{|l|}{ Sphaeriidae } & $*$ & 0.999 & & \multicolumn{5}{|c|}{ Sericostomatidae } & 0.266 \\
\hline \multicolumn{3}{|c|}{ Gammaridae (incl. Crangonyctidae) } & $*$ & 0.887 & & \multicolumn{5}{|c|}{ Nemouridae } & 0.235 \\
\hline \multicolumn{3}{|c|}{ Glossiphoniidae } & * & 0.883 & & \multicolumn{5}{|c|}{ Coenagriidae } & 0.232 \\
\hline \multicolumn{3}{|c|}{ Hydrobiidae (incl. Bithyniidae) } & * & 0.879 & & \multicolumn{5}{|c|}{ Psychomyiidae (incl. Ecnomidae) } & 0.227 \\
\hline \multicolumn{4}{|c|}{ Limnephilidae } & 0.877 & & \multicolumn{5}{|c|}{ Calopterygidae } & 0.226 \\
\hline \multicolumn{4}{|l|}{ Baetidae } & 0.840 & & \multicolumn{5}{|c|}{ Dendrocoelidae } & 0.190 \\
\hline \multicolumn{3}{|l|}{ Asellidae } & * & 0.823 & & \multicolumn{5}{|c|}{ Gyrinidae } & 0.179 \\
\hline \multicolumn{4}{|l|}{ Elmidae } & 0.819 & & \multicolumn{5}{|c|}{ Heptageniidae } & 0.155 \\
\hline \multicolumn{3}{|l|}{ Erpobdellidae } & * & 0.808 & & \multicolumn{5}{|c|}{ Molannidae } & 0.133 \\
\hline \multicolumn{3}{|c|}{ Planariidae (incl. Dugesiidae) } & & 0.699 & & Hydrophilic & e (incl. & ydraenidae) & & & 0.130 \\
\hline Dytiscidae (incl. Nc & ridae) & & $*$ & 0.692 & & Lepidostom & tidae & & & & 0.102 \\
\hline Planorbidae & & & * & 0.669 & & Odontoceri & & & & & 0.079 \\
\hline Caenidae & & & & 0.583 & & Notonectid & & & & & 0.076 \\
\hline Simuliidae & & & & 0.580 & & Neritidae & & & & & 0.075 \\
\hline Haliplidae & & & & 0.556 & & Scirtidae $(=$ & elodida & & & & 0.072 \\
\hline Lymnaeidae & & & * & 0.551 & & Perlodidae & & & & & 0.060 \\
\hline Tipulidae & & & & 0.511 & & Dryopidae & & & & & 0.036 \\
\hline Leptoceridae & & & & 0.499 & & Beraeidae & & & & & 0.023 \\
\hline Physidae & & & & 0.495 & & Hirudinidae & & & & & 0.021 \\
\hline Ancylidae (incl. Ac & loxidae) & & $*$ & 0.478 & & Phyrganeid & & & & & 0.021 \\
\hline Valvatidae & & & & 0.472 & & Brachycent & & & & & 0.020 \\
\hline Hydropsychidae & & & & 0.470 & & Aphelochei & & & & & 0.019 \\
\hline Hydroptilidae & & & & 0.426 & & Gerridae & & & & & 0.019 \\
\hline Ephemerellidae & & & & 0.413 & & Viviparidae & & & & & 0.019 \\
\hline Sialidae & & & & 0.402 & & Platycnemi & & & & & 0.018 \\
\hline Corixidae & & & & 0.377 & & Nepidae & & & & & 0.016 \\
\hline Polycentropodidae & & & & 0.364 & & Leuctridae & & & & & 0.008 \\
\hline Ephemeridae & & & & 0.363 & & Taenioptery & idae & & & & 0.003 \\
\hline Rhyacophilidae (in & Glossos & natidae) & & 0.338 & & Unionidae & & & & & 0.003 \\
\hline Leptophlebiidae & & & & 0.334 & & & & & & & \\
\hline Threshold $P_{t}$ & 0 & 0.1 & 0.2 & 0.3 & 0.4 & 0.5 & 0.6 & 0.7 & 0.8 & 0.9 & \\
\hline $\mathrm{O}$ & 13 & 13 & 13 & 12 & 12 & 11 & 10 & 8 & 8 & 3 & \\
\hline E & 23.3 & 22.2 & 21.8 & 20.1 & 18.3 & 14.7 & 11.9 & 9.8 & 9.8 & 3 & \\
\hline$O / E_{T A X A}$ & 0.56 & 0.57 & 0.60 & 0.60 & 0.66 & 0.75 & 0.84 & 0.82 & 0.82 & 1.00 & \\
\hline
\end{tabular}


Table 4 Distribution of $\mathrm{O} / \mathrm{E}_{\mathrm{TAXA}}$ and $\mathrm{O} / \mathrm{E}_{\mathrm{ASPT}}$ values for the 614 RIVPACS reference sites (spring samples) in terms of (a) standard deviation (SD) and (b) lower 10-percentile value.

\begin{tabular}{lcccccccccc}
\hline & & & & \multicolumn{8}{c}{ Threshold $P_{t}$} \\
(a) $\mathrm{SD}(\mathrm{O} / \mathrm{E})$ & 0 & 0.1 & 0.2 & 0.3 & 0.4 & 0.5 & 0.6 & 0.7 & 0.8 & 0.9 \\
$O / E_{T A X A}$ & 0.214 & 0.209 & 0.202 & 0.194 & 0.182 & 0.168 & 0.141 & 0.129 & 0.106 & 0.094 \\
$O / E_{A S P T}$ & 0.085 & 0.083 & 0.079 & 0.075 & 0.072 & 0.065 & 0.057 & 0.052 & 0.051 & 0.103 \\
& & & & & & & & & & \\
(b) Lower 10\% & & & & & & & & & & \\
O/E $E_{T A X A}$ & 0.747 & 0.775 & 0.775 & 0.772 & 0.777 & 0.804 & 0.811 & 0.848 & 0.871 & 0.883 \\
$O / E_{A S P T}$ & 0.892 & 0.884 & 0.893 & 0.905 & 0.906 & 0.917 & 0.931 & 0.936 & 0.944 & 0.983 \\
\hline
\end{tabular}

Table 5 Average replicate standard deviation (SD) in O/E across all sites and seasons and for classes of replicate mean value of $\mathrm{O} / \mathrm{E}$, using a range of expected probability thresholds $P_{t}$ for (a) $\mathrm{O} / \mathrm{E}_{\mathrm{TAXA}}$ and (b) $\mathrm{O} / \mathrm{E}_{\mathrm{ASPT}}$ based on all single season samples from the BAMS sites.

\begin{tabular}{|c|c|c|c|c|c|c|c|}
\hline \multirow{3}{*}{$\begin{array}{c}\text { Threshold } \\
P_{t}\end{array}$} & \multicolumn{7}{|c|}{ (a) Replicate mean of $\mathrm{O} / \mathrm{E}_{\mathrm{TAXA}}$} \\
\hline & \multicolumn{2}{|c|}{$<0.6$} & \multicolumn{2}{|c|}{$0.6-0.9$} & \multicolumn{2}{|c|}{$>0.9$} & \multirow{2}{*}{$\frac{\text { Overall }}{\mathrm{SD}}$} \\
\hline & SD & $n$ & SD & $n$ & $\mathrm{SD}$ & $n$ & \\
\hline 0.0 & 0.063 & 29 & 0.074 & 15 & 0.115 & 4 & 0.072 \\
\hline 0.1 & 0.066 & 29 & 0.073 & 16 & 0.113 & 3 & 0.072 \\
\hline 0.2 & 0.070 & 28 & 0.071 & 16 & 0.109 & 4 & 0.074 \\
\hline 0.3 & 0.073 & 26 & 0.069 & 18 & 0.087 & 4 & 0.073 \\
\hline 0.4 & 0.058 & 22 & 0.087 & 22 & 0.080 & 4 & 0.074 \\
\hline 0.5 & 0.060 & 19 & 0.102 & 19 & 0.083 & 10 & 0.084 \\
\hline 0.6 & 0.078 & 19 & 0.096 & 19 & 0.088 & 10 & 0.087 \\
\hline 0.7 & 0.072 & 17 & 0.102 & 20 & 0.065 & 11 & 0.084 \\
\hline 0.8 & 0.079 & 16 & 0.112 & 20 & 0.064 & 12 & 0.091 \\
\hline 0.9 & 0.074 & 12 & 0.133 & 12 & 0.091 & 14 & 0.109 \\
\hline
\end{tabular}

(b) Replicate mean of $\mathrm{O} / \mathrm{E}_{\mathrm{ASPT}}$

\begin{tabular}{cccccccc} 
Threshold & \multicolumn{2}{c}{$<0.7$} & \multicolumn{2}{c}{$0.7-0.9$} & \multicolumn{2}{c}{$>0.9$} & Overall \\
\cline { 2 - 8 }$P_{t}$ & SD & $n$ & SD & $n$ & SD & $n$ & SD \\
\hline 0.0 & 0.049 & 17 & 0.043 & 22 & 0.058 & 9 & 0.048 \\
0.1 & 0.051 & 17 & 0.041 & 22 & 0.045 & 9 & 0.046 \\
0.2 & 0.055 & 18 & 0.048 & 21 & 0.042 & 9 & 0.050 \\
0.3 & 0.056 & 16 & 0.044 & 20 & 0.048 & 12 & 0.049 \\
0.4 & 0.059 & 14 & 0.043 & 20 & 0.039 & 14 & 0.047 \\
0.5 & 0.063 & 12 & 0.049 & 19 & 0.039 & 19 & 0.050 \\
0.6 & 0.066 & 10 & 0.055 & 19 & 0.042 & 19 & 0.053 \\
0.7 & 0.094 & 9 & 0.065 & 17 & 0.041 & 22 & 0.063 \\
0.8 & 0.097 & 10 & 0.077 & 14 & 0.049 & 24 & 0.070 \\
0.9 & 0.067 & 11 & 0.138 & 11 & 0.050 & 26 & 0.082 \\
\hline
\end{tabular}


Table 6 Percentage of the $n$ GQA sites with each intensity of overall (and organic) environmental stress which were assessed as being biologically impaired (i.e. site $\mathrm{O} / \mathrm{E}<$ lower 10-percentile $\mathrm{O} / \mathrm{E}$ of reference sites) using $\mathrm{O} / \mathrm{E}$ based on each threshold probability $P_{t}$.

\begin{tabular}{|c|c|c|c|c|c|c|c|c|c|c|c|}
\hline \multirow{4}{*}{$\begin{array}{c}\text { O/E } \\
\text { Overall stres }\end{array}$} & \multirow[b]{2}{*}{$n$} & \multicolumn{10}{|c|}{ Threshold $P_{t}$} \\
\hline & & 0 & 0.1 & 0.2 & 0.3 & 0.4 & 0.5 & 0.6 & 0.7 & 0.8 & 0.9 \\
\hline & & & & & & & & & & & \\
\hline & & & & & & & & & & & \\
\hline Unstressed & 1373 & 16 & 20 & 20 & 18 & 17 & 18 & 17 & 20 & 21 & 20 \\
\hline Light & 1944 & 35 & 39 & 38 & 36 & 34 & 35 & 32 & 35 & 36 & 33 \\
\hline Moderate & 1724 & 55 & 59 & 58 & 56 & 55 & 56 & 53 & 55 & 56 & 51 \\
\hline Severe & 711 & 66 & 69 & 68 & 66 & 65 & 66 & 64 & 66 & 64 & 60 \\
\hline$O / E_{A S P T}$ & & & & & & & & & & & \\
\hline Overall stres & & & & & & & & & & & \\
\hline Unstressed & 1373 & 12 & 11 & 12 & 13 & 12 & 12 & 14 & 13 & 15 & 22 \\
\hline Light & 1944 & 33 & 32 & 33 & 34 & 33 & 32 & 32 & 29 & 28 & 34 \\
\hline Moderate & 1724 & 57 & 54 & 56 & 56 & 54 & 53 & 53 & 47 & 46 & 48 \\
\hline Severe & 711 & 72 & 70 & 70 & 69 & 69 & 68 & 66 & 62 & 59 & 60 \\
\hline Organic inpu & & & & & & & & & & & \\
\hline Unstressed & 2700 & 24 & 22 & 23 & 25 & 24 & 24 & 26 & 23 & 24 & 31 \\
\hline Light & 1008 & 35 & 33 & 35 & 36 & 35 & 34 & 33 & 29 & 30 & 33 \\
\hline Moderate & 1401 & 57 & 54 & 55 & 55 & 53 & 52 & 51 & 45 & 43 & 43 \\
\hline Severe & 643 & 79 & 78 & 77 & 78 & 75 & 74 & 72 & 69 & 65 & 68 \\
\hline
\end{tabular}

Table 7 Percentage of all non-zero expected probabilities of occurrence amongst all GQA sites in each expected probability class $(<0.2,0.2-0.5,0.5-0.8,>0.8)$, separately for all of the families in each class $(1-4,5-7,8-10)$ of BMWP score.

\begin{tabular}{cccccc}
\hline \multirow{2}{*}{$\begin{array}{c}\text { BMWP } \\
\text { score }\end{array}$} & \multirow{2}{*}{$\begin{array}{c}\text { Number of } \\
\text { families }\end{array}$} & \multicolumn{4}{c}{ Expected probability } \\
\cline { 3 - 6 } & 15 & $27 \%$ & $21 \%$ & $17 \%$ & $35 \%$ \\
$5-4$ & 35 & $39 \%$ & $23 \%$ & $19 \%$ & $19 \%$ \\
$8-10$ & 32 & $57 \%$ & $27 \%$ & $11 \%$ & $5 \%$ \\
Overall & 82 & $42 \%$ & $24 \%$ & $16 \%$ & $18 \%$ \\
\hline
\end{tabular}




\section{Figure legends}

Fig. 1 Illustration of the change in $\mathrm{O} / \mathrm{E}$ for number of taxa in relation to the threshold expected probability $P_{t}$ for three replicate spring samples $(\bullet, \boldsymbol{\Delta}$ and $\boldsymbol{\square})$ from the BAMS site at Swarkestone on Cuttle Brook.

Fig. 2 Boxplot distributions of the O/E values for the 614 RIVPACS reference sites (spring samples) using a range of expected probability thresholds $P_{t}$ for (a) $\mathrm{O} / \mathrm{E}_{\mathrm{TAXA}}$ and (b) $\mathrm{O} / \mathrm{E}_{\mathrm{ASPT}}$. Boxes denote inter-quartile ranges, horizontal bars denote medians and solid circles denote mean values.

Fig. 3 Average replicate standard deviation (SD) in $\mathrm{O} / \mathrm{E}$ for classes of replicate mean value of O/E, using expected probability thresholds $P_{t}$ of $0.0,0.1,0.3,0.5,0.7$ and 0.9 for (a) $\mathrm{O} / \mathrm{E}_{\mathrm{TAXA}}$ and (b) $\mathrm{O} / \mathrm{E}_{\mathrm{ASPT}}$ based on all single season samples from the BAMS sites.

Fig. 4 Median difference in $\mathrm{O} / \mathrm{E}$ (i.e. $\mathrm{O} / \mathrm{E}$ using a threshold $P_{t}$ minus $\mathrm{O} / \mathrm{E}$ for $P_{t}=0.0$ ) for classes of $n$ GQA sites grouped by 0.1 intervals of their $\mathrm{O} / \mathrm{E}$ value for $P_{t}=0.0$. Thresholds $P_{t}$ : $0.1(*), 0.3(\circ), 0.5(\bullet), 0.7(\boldsymbol{\bullet}), 0.9(\boldsymbol{\Delta})$ for $(\mathrm{a}) \mathrm{O} / \mathrm{E}_{\mathrm{TAXA}}$ and (b) $\mathrm{O} / \mathrm{E}_{\mathrm{ASPT}}$ based on spring samples from the GQA sites.

Fig. 5 Median difference in $\mathrm{O} / \mathrm{E}$ (i.e. $\mathrm{O} / \mathrm{E}$ using a threshold $P_{t}$ minus $\mathrm{O} / \mathrm{E}$ for $P_{t}=0.5$ ) for classes of $n$ GQA sites grouped by 0.1 intervals of their $\mathrm{O} / \mathrm{E}$ value for $P_{t}=0.5$. Thresholds $P_{t}$ : $0.0(\bullet), 0.1(*), 0.3(\mathrm{O}), 0.7(\bullet), 0.9(\mathbf{\Delta})$ for (a) $\mathrm{O} / \mathrm{E}_{\mathrm{TAXA}}$ and (b) $\mathrm{O} / \mathrm{E}_{\mathrm{ASPT}}$ based on spring samples from the GQA sites.

Fig. 6 Boxplots of the distribution of the average expected probability of occurrence for each BMWP family across all 5752 GQA sites, for families grouped by their BMWP score (1-4, 57, 8-10). Boxes denote inter-quartile ranges, horizontal bars denote medians (value indicated) and circles denote average expected probabilities for individual families. 


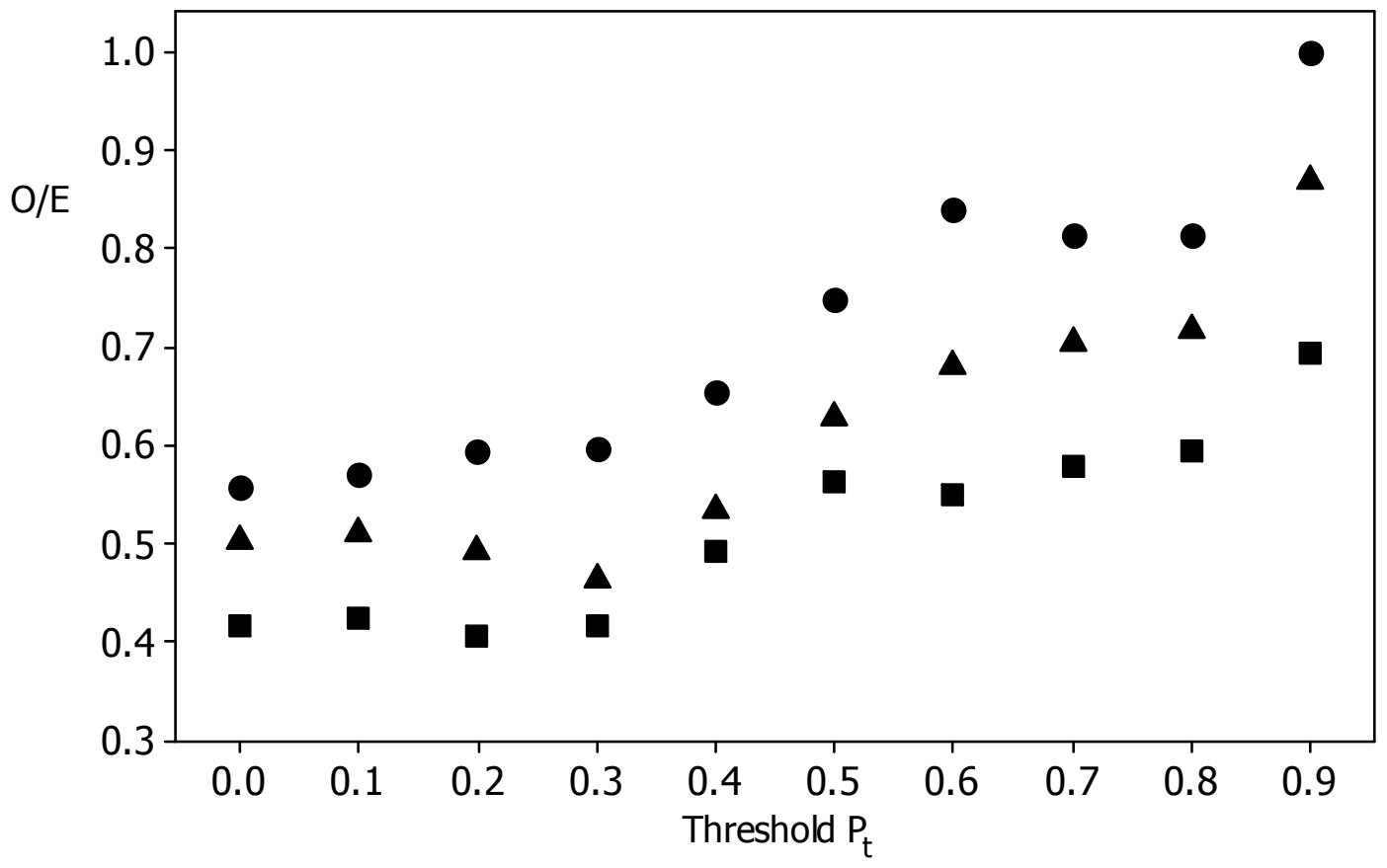

Fig. 1 Illustration of the change in $\mathrm{O} / \mathrm{E}$ for number of taxa in relation to the threshold expected probability $P_{t}$ for three replicate spring samples $(\bullet, \boldsymbol{\Delta}$ and $\boldsymbol{\square})$ from the BAMS site at Swarkestone on Cuttle Brook. 

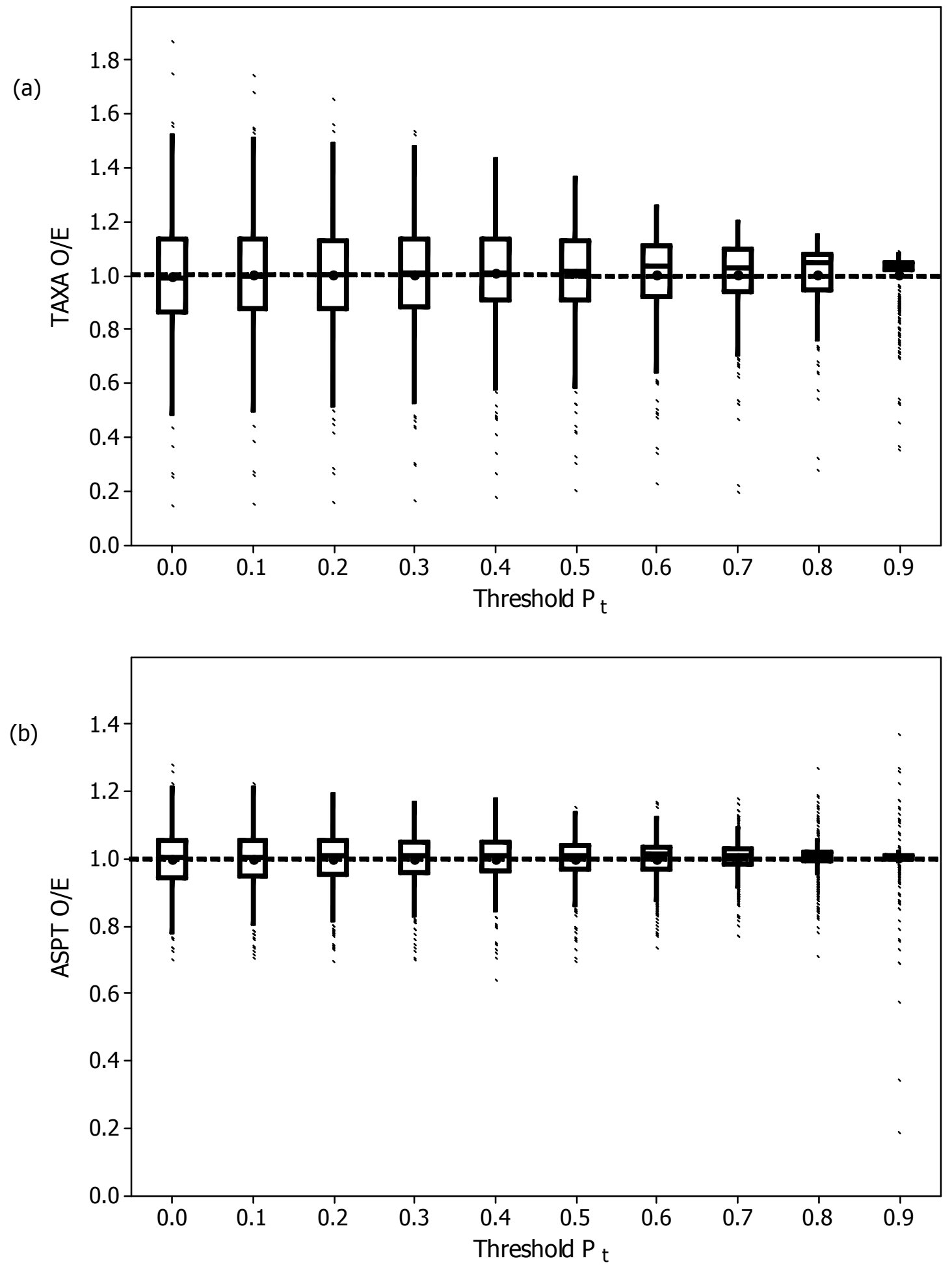

Fig. 2 Boxplot distributions of the O/E values for the 614 RIVPACS reference sites (spring samples) using a range of expected probability thresholds $P_{t}$ for (a) $\mathrm{O} / \mathrm{E}_{\mathrm{TAXA}}$ and (b) $\mathrm{O} / \mathrm{E}_{\mathrm{ASPT}}$. Boxes denote inter-quartile ranges, horizontal bars denote medians and solid circles denote mean values. 

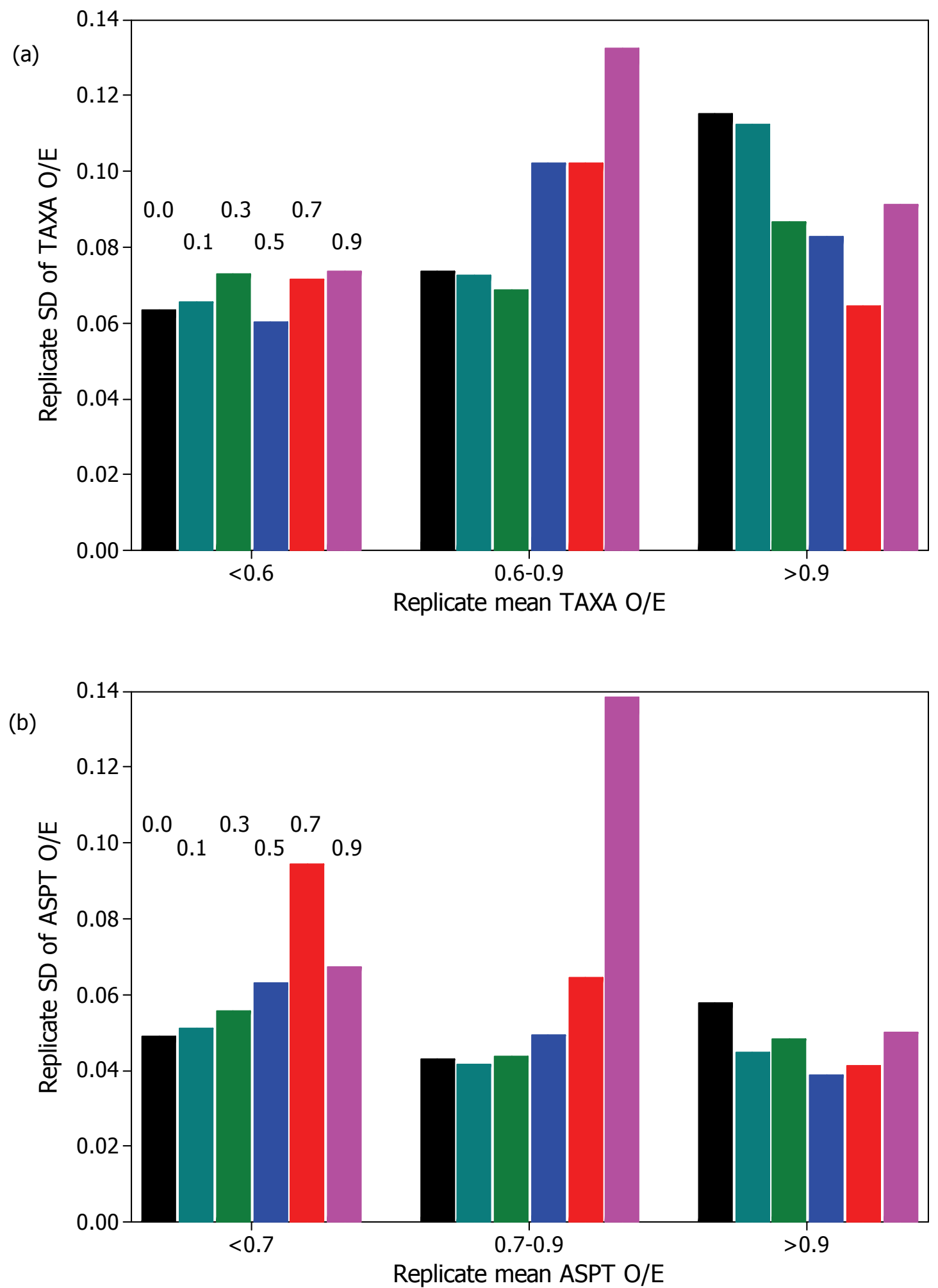

Fig. 3 Average replicate standard deviation (SD) in O/E for classes of replicate mean value of $\mathrm{O} / \mathrm{E}$, using expected probability thresholds $P_{t}$ of $0.0,0.1,0.3,0.5,0.7$ and 0.9 for (a) $\mathrm{O} / \mathrm{E}_{\mathrm{TAXA}}$ and (b) $\mathrm{O} / \mathrm{E}_{\mathrm{ASPT}}$ based on all single season samples from the BAMS sites. 

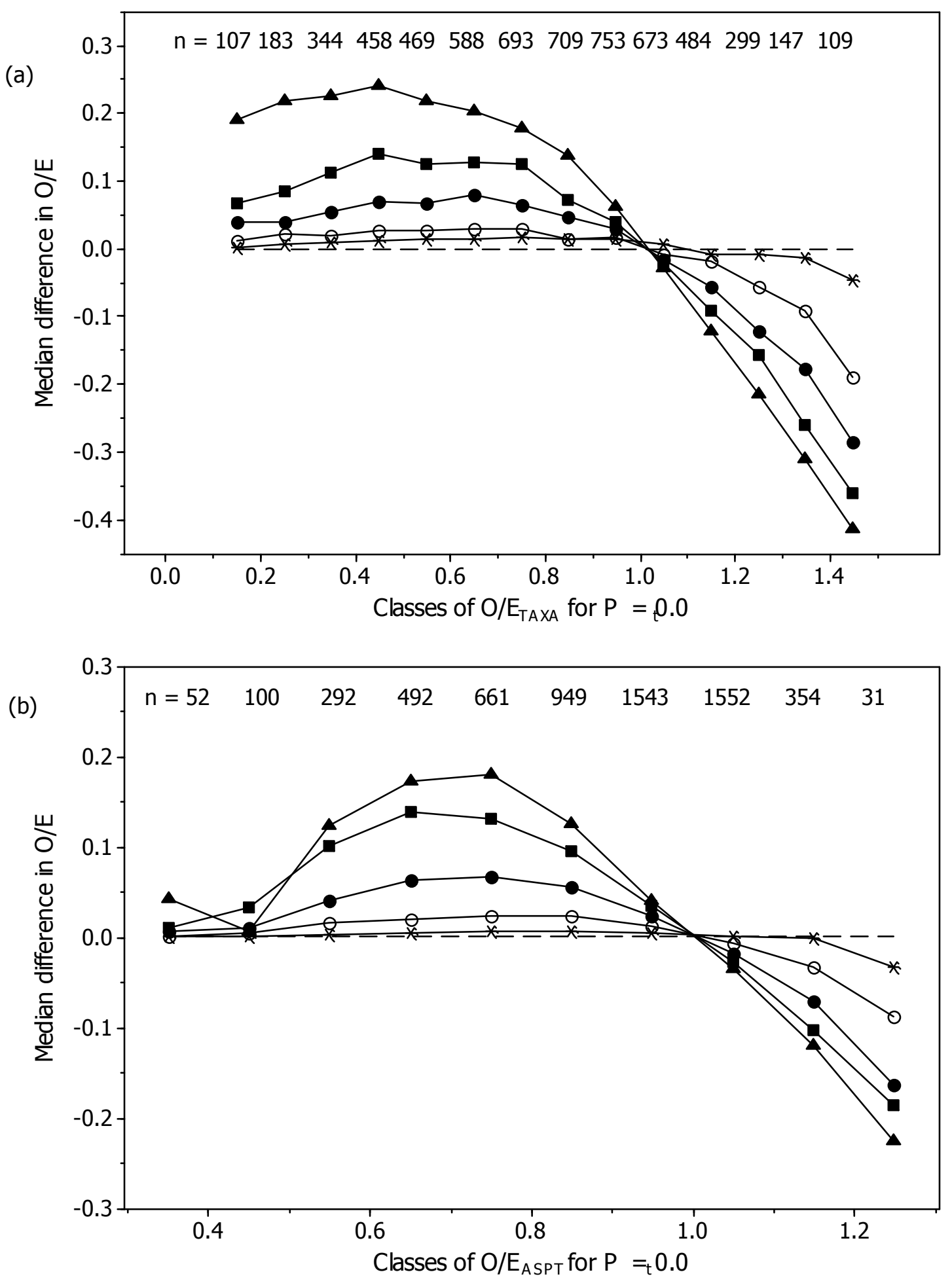

Fig. 4 Median difference in $\mathrm{O} / \mathrm{E}$ (i.e. $\mathrm{O} / \mathrm{E}$ using a threshold $P_{t}$ minus $\mathrm{O} / \mathrm{E}$ for $P_{t}=0.0$ ) for classes of $n$ GQA sites grouped by 0.1 intervals of their $\mathrm{O} / \mathrm{E}$ value for $P_{t}=0.0$. Thresholds $P_{t}$ : $0.1(*), 0.3(\circ), 0.5(\bullet), 0.7(\boldsymbol{\bullet}), 0.9(\boldsymbol{\Delta})$ for $(\mathrm{a}) \mathrm{O} / \mathrm{E}_{\mathrm{TAXA}}$ and (b) $\mathrm{O} / \mathrm{E}_{\mathrm{ASPT}}$ based on spring samples from the GQA sites. 

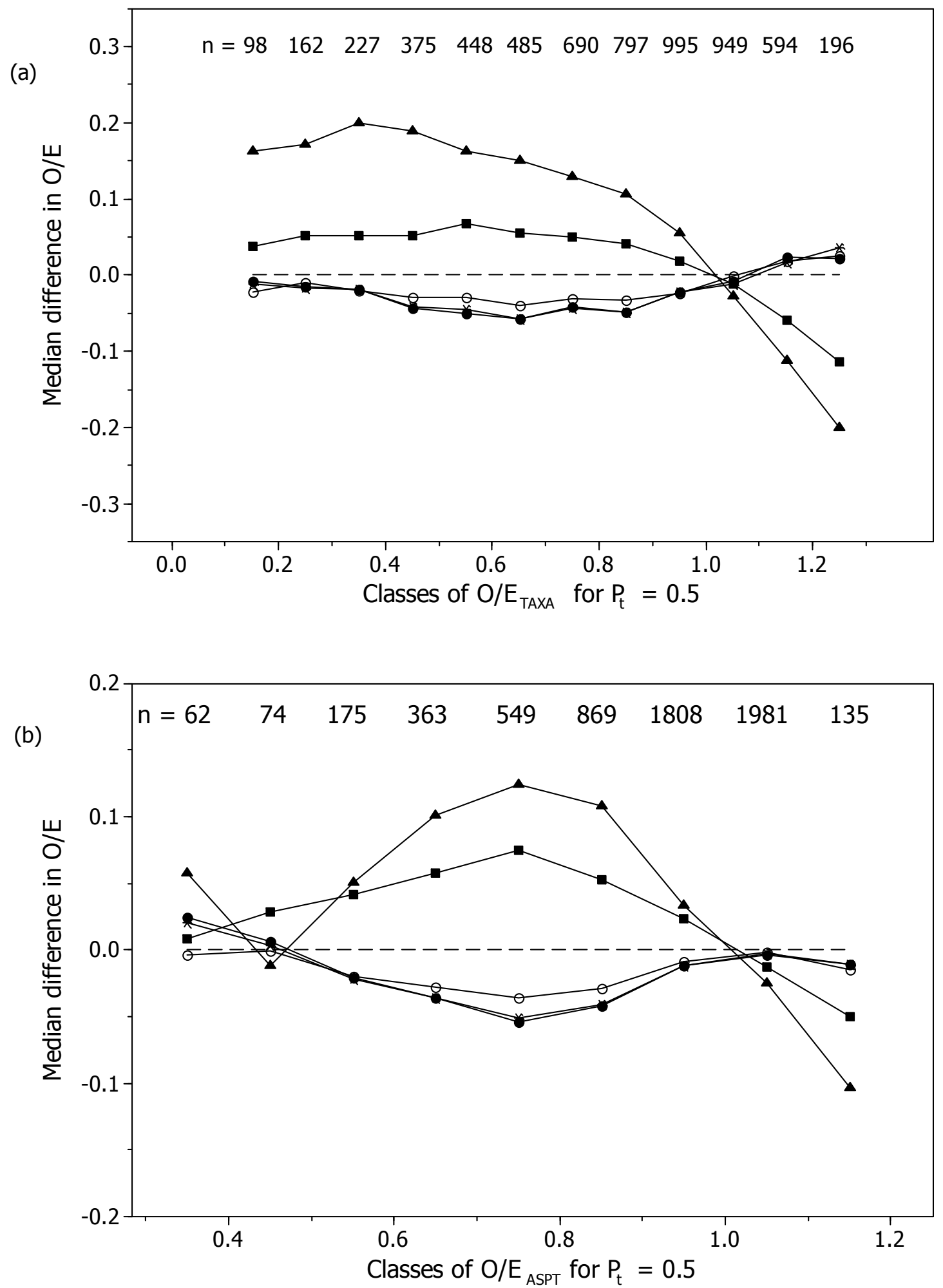

Fig. 5 Median difference in $\mathrm{O} / \mathrm{E}$ (i.e. $\mathrm{O} / \mathrm{E}$ using a threshold $P_{t}$ minus $\mathrm{O} / \mathrm{E}$ for $P_{t}=0.5$ ) for classes of $n$ GQA sites grouped by 0.1 intervals of their $\mathrm{O} / \mathrm{E}$ value for $P_{t}=0.5$. Thresholds $P_{t}$ : $0.0(\bullet), 0.1(*), 0.3(\circ), 0.7(\boldsymbol{\bullet}), 0.9(\boldsymbol{\Delta})$ for $(\mathrm{a}) \mathrm{O} / \mathrm{E}_{\mathrm{TAXA}}$ and (b) $\mathrm{O} / \mathrm{E}_{\mathrm{ASPT}}$ based on spring samples from the GQA sites. 


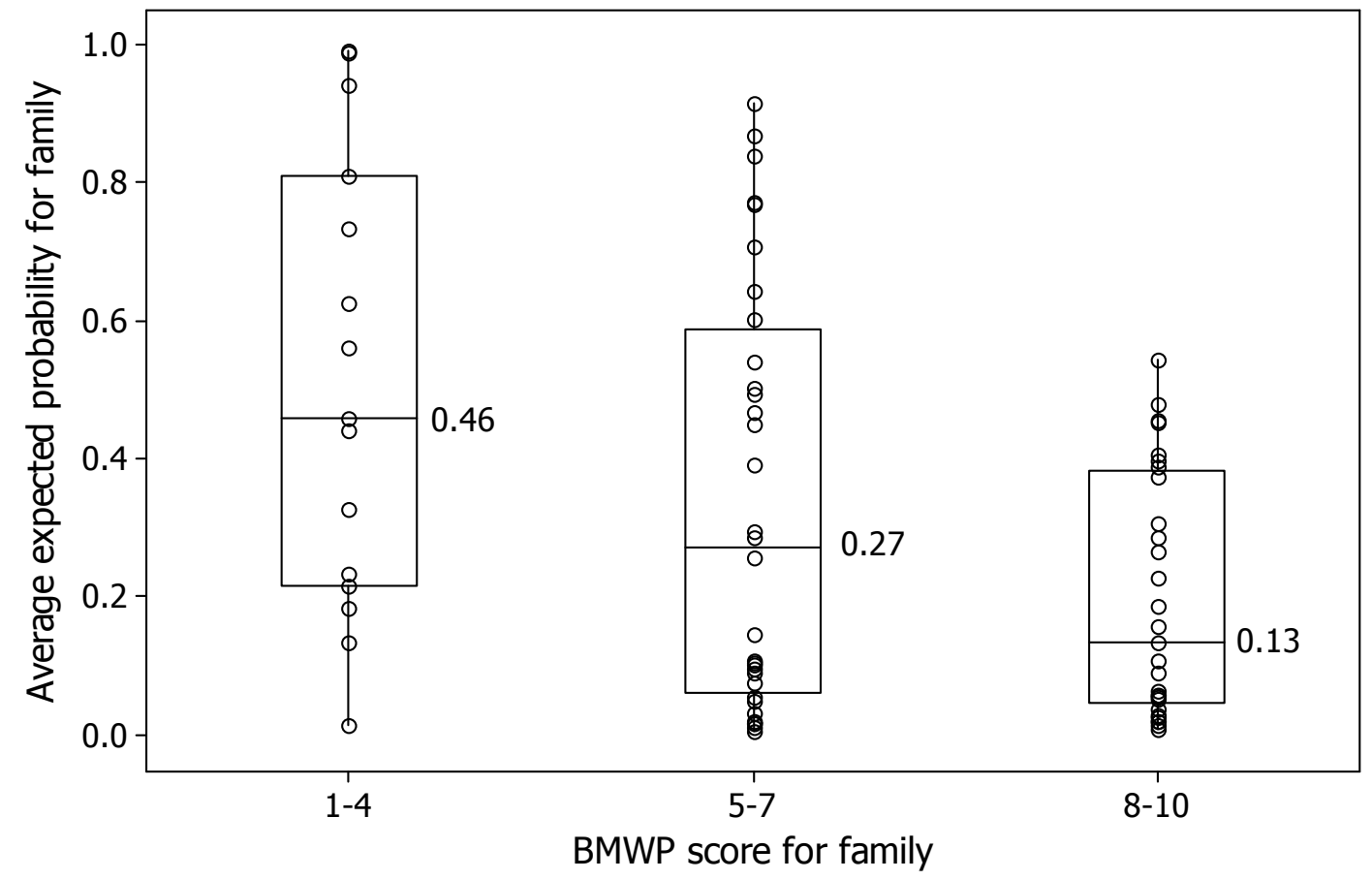

Fig. 6 Boxplots of the distribution of the average expected probability of occurrence for each BMWP family across all 5752 GQA sites, for families grouped by their BMWP score (1-4, 57, 8-10). Boxes denote inter-quartile ranges, horizontal bars denote medians (value indicated) and circles denote average expected probabilities for individual families. 